\title{
Model Action Plan for Nuclear Forensics and Nuclear Attribution
}

A draft product for

The International Technical Working Group

Intended as the basis for an IAEA TECDOC

M. J. Kristo, D. K. Smith, S. Niemeyer

Lawrence Livermore National Laboratory

G. B. Dudder

Pacific Northwest National Laboratory

U.S. Department of Energy

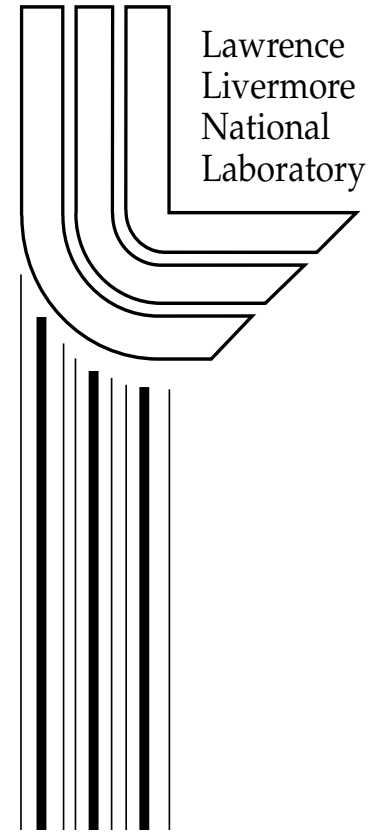

March 3, 2004 


\section{DISCLAIMER}

This document was prepared as an account of work sponsored by an agency of the United States Government. Neither the United States Government nor the University of California nor any of their employees, makes any warranty, express or implied, or assumes any legal liability or responsibility for the accuracy, completeness, or usefulness of any information, apparatus, product, or process disclosed, or represents that its use would not infringe privately owned rights. Reference herein to any specific commercial product, process, or service by trade name, trademark, manufacturer, or otherwise, does not necessarily constitute or imply its endorsement, recommendation, or favoring by the United States Government or the University of California. The views and opinions of authors expressed herein do not necessarily state or reflect those of the United States Government or the University of California, and shall not be used for advertising or product endorsement purposes.

This work was performed under the auspices of the U. S. Department of Energy by the University of California, Lawrence Livermore National Laboratory under Contract No. W-7405Eng-48. 


\title{
Model Action Plan for \\ Nuclear Forensics and Nuclear Attribution
}

\author{
A draft product for \\ The International Technical Working Group \\ Intended as the basis for an IAEA TECDOC
}

March 5, 2004

Michael J. Kristo, David K. Smith, and Sidney Niemeyer

Lawrence Livermore National Laboratory

Gordon B. Dudder

Pacific Northwest National Laboratory 


\section{TABLE OF CONTENTS}

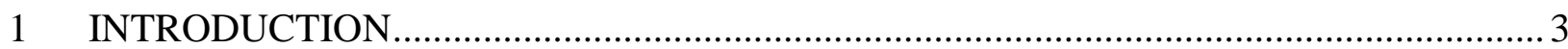

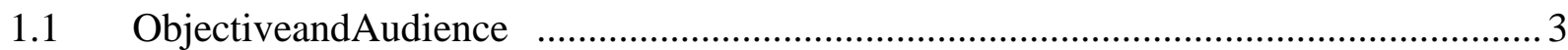

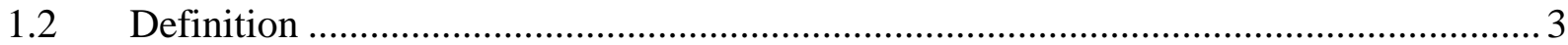

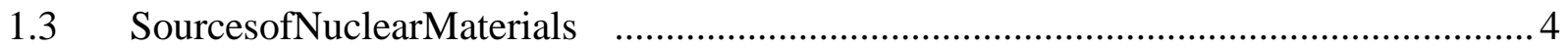

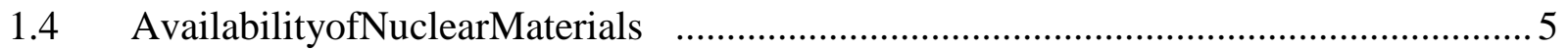

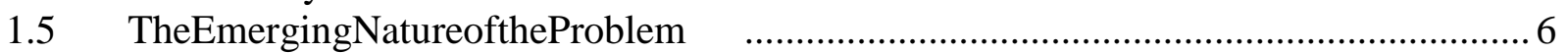

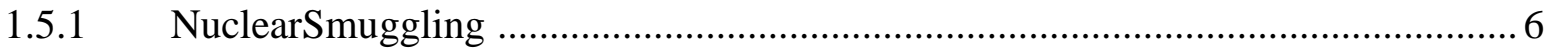

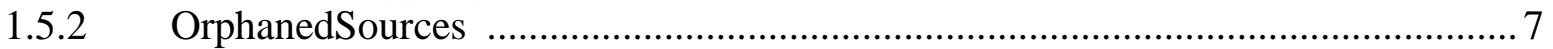

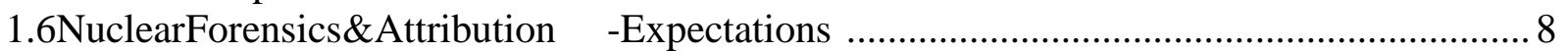

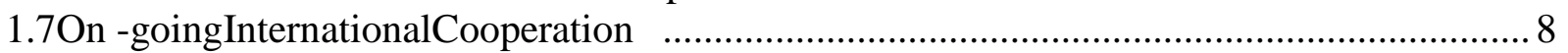

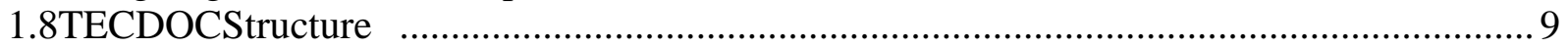

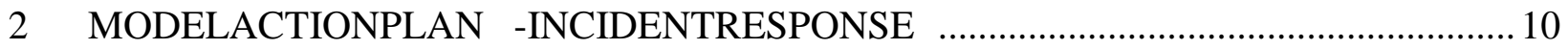

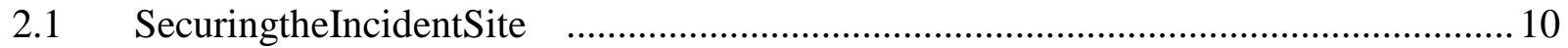

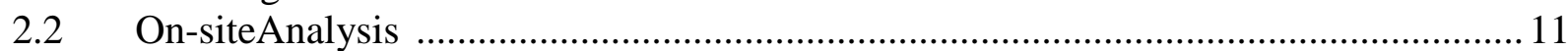

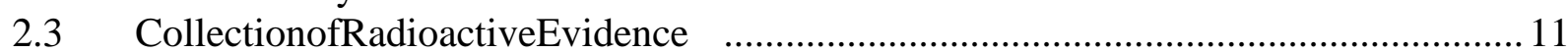

2.4 Collection of Traditional Forensic Evidence .............................................................. 13

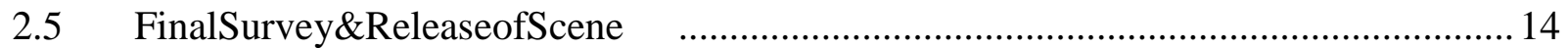

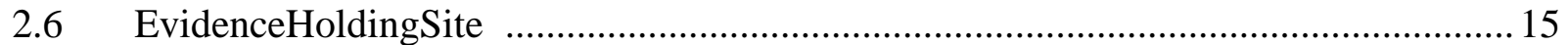

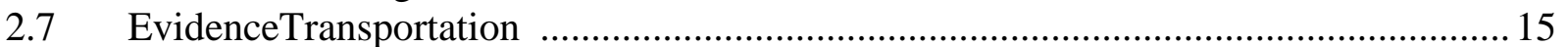

3 MODEL ACTION PLAN - LABORATORY SAMPLING \& DISTRIBUTION ….............. 17

3.1 The Nuclear Analysis Laboratory ……………...................................................... 17

3.2 The Forensic Management Team........................................................................... 18

3.3 Sampling and Aliquoting in the Nuclear Forensics Laboratory................................... 18

4 MODEL ACTION PLAN- RADIOACTIVE MATERIALS ANALYSIS ............................20

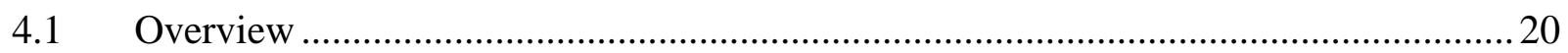

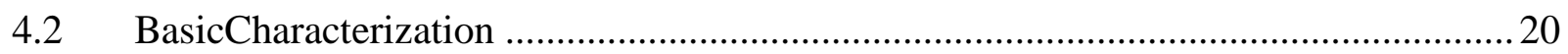

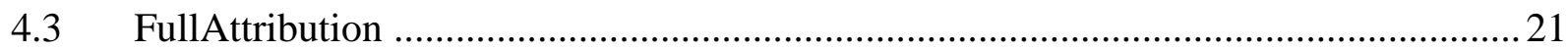

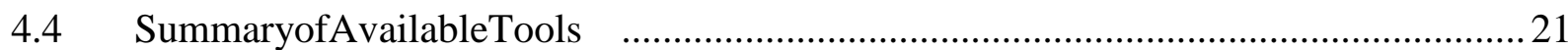

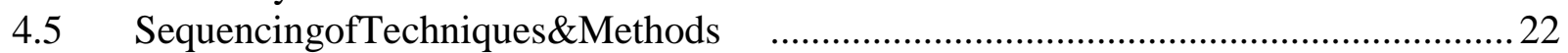

5 MODEL ACTION PLAN- TRADITIONAL FORENSIC ANALYSIS .............................23

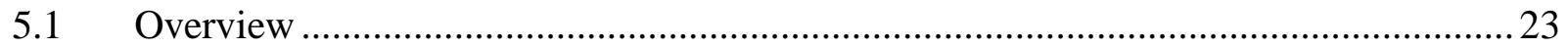

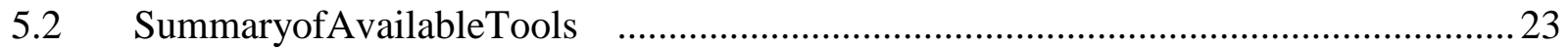

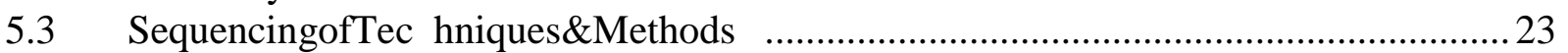

6 MODEL ACTION PLAN - CASE DEVELOPMENT …..................................................... 24

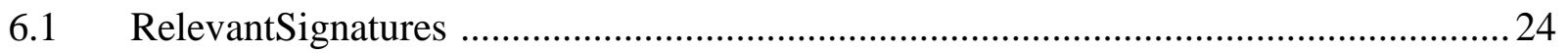

6.2 Cooperation with Other Nuclear Forensics Laboratories............................................2.

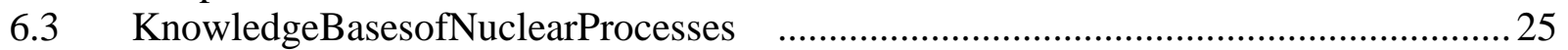

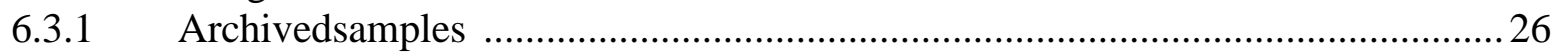

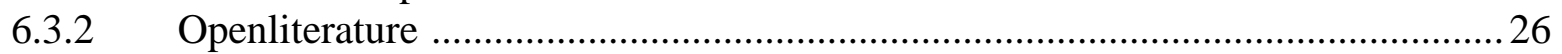

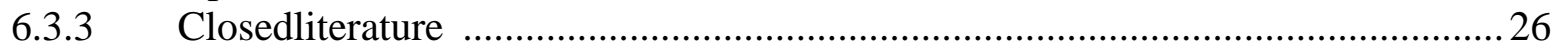

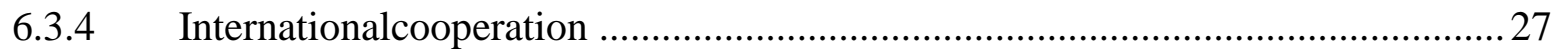

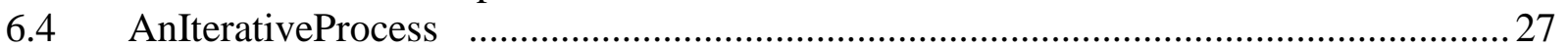

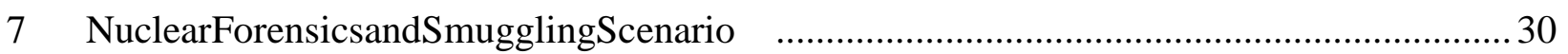

8 Attribution Confidence................................................................................................... 31 
8.1 Analytical Data Quality Objectives................................................................ 31

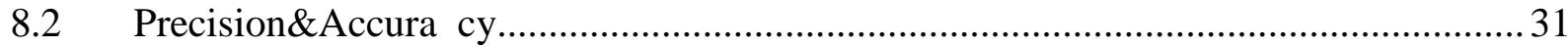

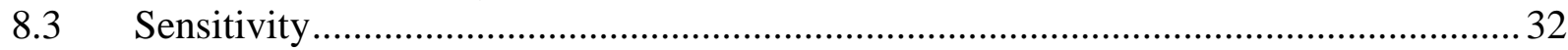

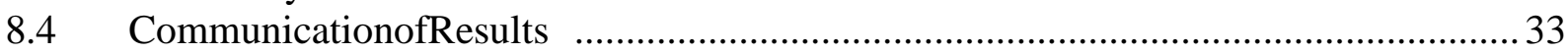

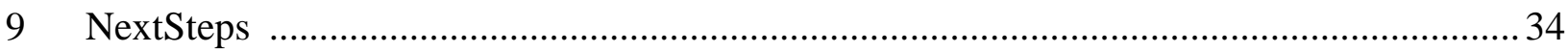

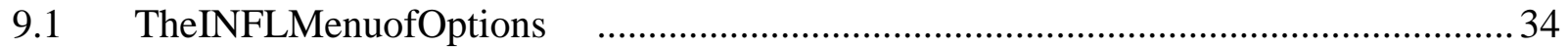

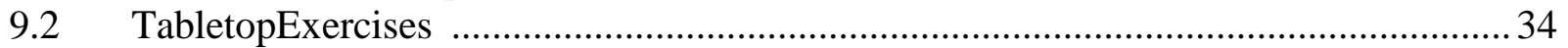

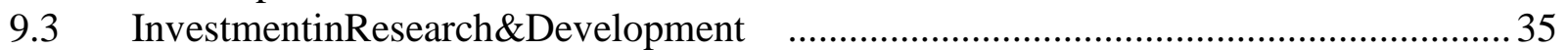

9.4 Nuclear Attribution as a Preventative Measure......................................................... 35

Appendix A. Menu of Options for ITWG Assisance ................................................... 36

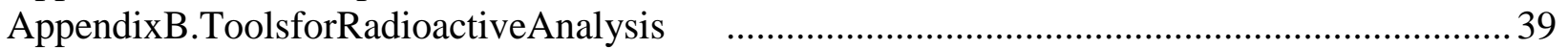

Appendix C. Examples of Traditional Forensic Evidence ................................................ 45

Appendix D. Nuclear Forensics and Smuggling Scenario ............................................... 47

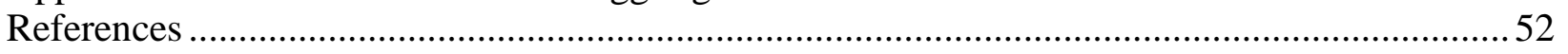




\section{INTRODUCTION}

\subsection{Objective and Audience}

Nuclear forensics and nuclear attribution have become increasingly important tools in the fight against illegal trafficking in nuclear and radiological materials. This technical report documents the field of nuclear forensics and nuclear attribution in a comprehensive manner, summarizing tools and procedures that have heretofore been described independently in the scientific literature. This report also provides national policy-makers, decision-makers, and technical managers with guidance for responding to incidents involving the interdiction of nuclear and radiological materials.

However, due to the significant capital costs of the equipment and the specialized expertise of the personnel, work in the field of nuclear forensics has been restricted so far to a handful of national and international laboratories. In fact, there are a limited number of specialists who have experience working with interdicted nuclear materials and affiliated evidence. Most of the laboratories that have the requisite equipment, personnel, and experience to perform nuclear forensic analysis are participants in the Nuclear Smuggling International Technical Working Group or ITWG (see Section 1.8). Consequently, there is a need to disseminate information on an appropriate response to incidents of nuclear smuggling, including a comprehensive approach to gathering evidence that meets appropriate legal standards and to developing insights into the source and routes of nuclear and radiological contraband. Appendix A presents a "Menu of Options" for other Member States to request assistance from the ITWG Nuclear Forensics Laboratories (INFL) on nuclear forensic cases.

\subsection{Definition}

Nuclear attribution utilizes many inputs, including results from nuclear forensic sample analyses, an understanding of radiochemical signatures, an understanding of environmental signatures, knowledge of the methods for production of special nuclear materials (SNM), knowledge of the nuclear weapons development pathway, information from intelligence sources, and information from law enforcement. The objective is to identify the source of nuclear and radiological materials used in illegal activities, determine the point-of-origin and routes of transit involving this material, and ultimately contribute to the prosecution of those responsible. Nuclear attribution is the integration of all relevant forms of information about a nuclear smuggling incident into data that can be readily analyzed and interpreted and that forms the basis of a confident response to the incident. The goal of nuclear attribution is to answer policy makers' needs, requirements, and questions in their framework for a given incident.

Nuclear forensic analysis is the process by which intercepted illicit nuclear and radiological materials and any associated materials, such as containers, are analyzed to provide clues to attribution. The goal of nuclear forensics analysis is to identify attribution indicators in interdicted nuclear and radiological samples or its surrounding environment, e.g., the container or transport vehicle. These indicators arise from known relationships between material 
characteristics and illicit activity. Thus, nuclear forensics analysis is more than the characterization of the material, which is the determination of the physical and chemical characteristics of the sample.

Both nuclear attribution and nuclear forensics can apply to nuclear or radiological materials. Hereafter, this document uses these terms interchangeably. The use of any of these terms alone in conjunction with nuclear attribution or nuclear forensics refers to all of them.

\subsection{Sources of Nuclear Materials}

Nuclear materials can be placed into 3 general categories: special nuclear materials (SNM), reactor fuel, and commercial radioactive sources (see Table 1). SNM includes the IAEA categories [1] of High Enriched Uranium (HEU), which itself includes the sub-category of Weapons-Grade Uranium (WGU) and Weapons Grade Plutonium (WGPu). WGPu also includes the sub-category of Super-Grade Plutonium or SGPu. Reactor fuel include the IAEA categories of Low Enriched Uranium (LEU), Reactor Grade Plutonium (RGPu), Fuel Grade Plutonium (FGPu), and MOX Grade Plutonium (MGPU).

SNM are materials that can be used to construct a nuclear weapon, including uranium with ${ }^{235} \mathrm{U}$ enrichments greater than $20 \%$ and plutonium with less than $7 \%$ of the ${ }^{240} \mathrm{Pu}$ isotope [1]. SNM make an especially attractive target for nations and terrorist organizations intent on developing a nuclear weapon, because possession of sufficient amounts of SNM eliminates the necessity of developing the advanced technology required for isotopic enrichment of uranium or plutonium separation. However, nuclear nations provide extensive security for their stockpiles of SNM in order to prevent the theft and terrorist use of nuclear materials or weapons.

Reactor fuel typically consists of uranium or a mixture of uranium and plutonium. Uranium is usually present as either uranium dioxide $\left(\mathrm{UO}_{2}\right)$ or uranium carbide and has either natural isotopic composition or is isotopically enriched to a few percent ${ }^{235} \mathrm{U}$. Plutonium is most often present as plutonium oxide $\left(\mathrm{PuO}_{2}\right)$. Most reactor fuel cannot be used to make a nuclear weapon without undergoing further enrichment in ${ }^{235} \mathrm{U}$ or chemical separation of the plutonium from the fuel. In addition, it is critical that the isotopic abundance of ${ }^{240} \mathrm{Pu}$ and ${ }^{242} \mathrm{Pu}$ be below a specific percentage in order to be weapons-usable. Therefore, plutonium from highly irradiated fuel may not be suitable for use in a nuclear weapon.

Spent reactor fuel is extremely radioactive and could be used as part of a radiological dispersal device (RDD) or so-called "dirty bomb." Fresh reactor fuel poses less of a radiation risk than spent fuel, although it is still dangerous if inhaled or ingested. Furthermorethe public perception of the radiation risk would most likely be much greater than the actual risk, so the psychological impacts engendered by detonation of RDD manufactured from fresh reactor fuel could be just as great that from a RDD made from spent fuel.

Commercial radioactive sources consist of chemically purified isotopes that decay by emission of alpha, beta, or gamma rays. These isotopes are most commonly produced in nuclear reactors, although some isotopes can be made in accelerators as well. They are produced either as a 
product of the fission process, e.g. ${ }^{137} \mathrm{Cs},{ }^{90} \mathrm{Sr}$, or as a result of neutron capture, e.g. ${ }^{60} \mathrm{Ni}$,

${ }^{241} \mathrm{Am}$. These radioactive isotopes are useful sources of radioactivity for medical diagnostics and therapy, non-destructive analysis of materials, sterilization of medical equipment and food, and generation of electricity in remote locations. The significant level of radioactivity in many commercial radioactive sources makes them attractive components of an RDD.

SNM

Table 1

Categories of Nuclear Materials [1]

\begin{tabular}{|c|c|}
\hline IAEA Categories & Characteristics \\
\hline High Enriched Uranium (HEU) & $>20 \%$ U-235 \\
\hline -- Weapons-Grade Uranium (WGU) & $\begin{array}{l}\text { Pure uranium metal } \\
>93 \% \text { U-235 }\end{array}$ \\
\hline Weapons-Grade Plutonium (WGPu) & $\begin{array}{l}\text { Pure plutonium metal } \\
<7 \% \text { Pu-240 }\end{array}$ \\
\hline -- Super-Grade Plutonium (SGPu) & $\begin{array}{l}\text { Pure plutonium metal } \\
<3 \% \text { Pu- } 240\end{array}$ \\
\hline
\end{tabular}

\section{Reactor Fuel}

\begin{tabular}{|l|l|}
\hline IAEA Categories & Characteristics \\
\hline Low Enriched Uranium (LEU) & $<20 \%$ (typically 3-5\%) U-235 \\
\hline Reactor-Grade Plutonium (RGPu) & $\begin{array}{l}\text { Produced in nuclear power reactors } \\
>19 \% \text { Pu-240 }\end{array}$ \\
\hline Fuel-Grade Plutonium (FGPu) & $\begin{array}{l}\text { Produced in nuclear reactors } \\
>7 \% \text { and }<19 \% \text { Pu-240 }\end{array}$ \\
\hline MOX-grade Plutonium (MGPu) & $\begin{array}{l}\text { Recycled from mixed (uranium + plutonium) } \\
\text { oxide fuel } \\
\end{array}$ \\
\hline
\end{tabular}

\section{Radioactive Sources}

\begin{tabular}{|l|l|}
\hline Typical Uses & Common Constituents \\
\hline Medical Diagnostic Sources & Short-lived radioisotopes \\
\hline Radiotherapy Sources & Co-60 and Cs-137 \\
\hline Irradiators/Sterilizers & Co-60 and Cs-137 \\
\hline Radiography/NDT & Ir-192 \\
\hline Gauging & Co-60, Cs-137, Am-241 \\
\hline Radioisotope Thermoelectric Generators (RTG) & Pu-238, Cm-244, and Sr-90 \\
\hline
\end{tabular}

\subsection{Availability of Nuclear Materials}

Special nuclear materials are tightly controlled by the producing nations. However, political and economic turmoil can contribute to conditions where even the most rigorous controls can falter. Commercial reactor fuel is also strictly controlled, because of the large amount of fuel used in power reactors. Although reactor fuel is not used directly in nuclear weapons, it would make an attractive feedstock for a rogue enrichment process. Nuclear fuel is also a valuable asset; nuclear fuel assemblies can cost in the range of 500,000 USD. 
Research reactor fuel tends not to be as tightly controlled as commercial reactor fuel. Research reactors are located at universities, institutes, and private companies where security is often the minimum required by law. Many research reactors have been shut down and security remains as an additional duty for already burdened faculty or staff. However, security of the research reactor fuel is especially important, because research reactor fuel is often enriched in ${ }^{235} \mathrm{U}$ to weapons-grade levels in order to achieve a high neutron flux. "Reduced Enrichment for Research and Test Reactors" (RERTR) programs in the United States [2] and Russia [3] attempt to mitigate the risk presented by these reactors by supplying specially designed high density, low-enrichment fuel to replace the weapons-grade fuel. The weapons-grade fuel is then returned to the U. S. or Russia for blending into reduced enrichment fuel.

Commercial radioactive sources are widely available. These sources vary widely in both the level and type (alpha, beta, gamma) of radiation that they emit and, therefore, vary in the potential radiological hazard that they pose. Those sources with low levels of radioactivity, such as the ${ }^{241} \mathrm{Am}$ sources used in building smoke detectors, tend to be more widely available and less tightly controlled than sources with high levels of radioactivity, such as ${ }^{60}$ Co sources used in nuclear medicine. Correspondingly, the threat posed by the ubiquitous, low-level sources is much less than that posed by the high-level sources. Until recently, governments have tended to focus more on the safety aspects of these radioactive sources and less on the security aspects. The regulations governing accounting and control of commercial radioactive sources vary from country to country, but are typically less strict than those governing reactor fuel. Consequently, it has been estimated that hundreds of sources are orphaned around the world each year [4-5].

Both irradiated reactor fuel and high-level commercial radioactive sources present technical difficulties for the potential manufacturer of a RDD. The same high level of radioactivity that makes them attractive material for a RDD also makes them dangerous to the terrorist who transports the material or fashions it into an RDD. The most intense radiation sources (a dose of $\sim 400-600$ rem, $\sim 4-6 \mathrm{~Sv}$ over several minutes) might kill or disable even a suicide bomber before completion of his work. Therefore, sources of moderate to low radioactivity may be more attractive as an RDD component. Since the primary purpose of a RDD is social disruption, the psychological effects of the use of a radiological device, even involving a weapon involving low doses, will be considerable.

\subsection{The Emerging Nature of the Problem}

\subsubsection{Nuclear Smuggling}

Incidents of illegal trafficking in nuclear materials have occurred for many years. A database kept by the United States Department of Energy includes cases from as early as 1966. However, until recently, these cases were almost always frauds. There has been a great rise in the number of reported nuclear smuggling cases since 1991. Although many of these cases are frauds as well, there has been a corresponding increase in the number of cases believed to be true or in which material was actually seized [6]. 
At the same time, there have been an increasing number of countries that seek to develop nuclear weapons and so scour world markets for the necessary expertise, equipment, and material. In order to avoid the scrutiny and condemnation of the world, these countries have tended to operate in the black markets devoted to illegal arms. In addition, the terrorist attacks of September 11, 2001, have focused world attention on terrorist groups, their aims, and their methods. For example, captured Al Qaeda documents showed serious research into the feasibility of obtaining or developing nuclear and RDD weapons [7]. In 1995, a Chechen rebel

leader directed a Russian television crew to a container with a small amount of ${ }^{137} \mathrm{Cs}$, presumably as a warning of potential RDD attacks in the future [8].

Although it is difficult to predict the future course of illicit trafficking in nuclear and radiological materials, increasingly such activities are viewed as significant threats that merit the development of special capabilities. As early as April,1996, nuclear forensics was recognized at the G-8 Summit in Moscow as an element of an illicit nuclear trafficking program. Given international events over the past several years, the value and need for nuclear forensics seems greater than ever.

\subsubsection{Orphaned Sources}

"Orphaned" sources are radioactive sources that have been abandoned, or are just being ignored, by their legitimate owner and have, therefore, fallen outside of any formal administrative controls. These orphaned sources are easily diverted for more sinister purposes. The lack of accountability for such sources, as well as the inherent expense and bureaucracy involved in safely and securely disposing of such sources, can lead to their abandonment.

Orphaned radioactive sources have been found in scrap metal yards or in recycling operations [910]. In at least one case, an end customer detected significant excess radioactivity in steel girders that was traced to the inadvertent recycling of a commercial source. More often, though, these orphaned sources will become part of the general waste stream from a facility and end up in the local landfill.

Commercial enterprises that use and control these radioactive sources may cease operations and go out of business. In such circumstances, corporate knowledge regarding these sources is lost as technical personnel are dismissed and move to other endeavors. Management is often unconcerned about the ultimate disposition of these radioactive sources. Turnover of faculty and students and changing research priorities may also similarly plague academic and university settings.

In some cases, sources will remain unsecured on the premises. In other cases, individuals unknowledgeable about the safety and security risks of the sources may determine their fate. The widespread contamination of Goiania, Brazil in 1987 with ${ }^{137} \mathrm{Cs}$ involved an unsecured radiotherapy source from an insolvent business, and subsequent scavenging and disposal by people unknowledgeable about the source and its risks [11]. 


\subsection{Nuclear Forensics \& Attribution - Expectations}

Determining how and where legitimate control of nuclear material was lost and tracing the route of the material from diversion through interdiction are important goals for any nuclear attribution. It is equally important to determine whether additional devices or materials that pose a threat to public safety are available on the black market. The answer to these questions depends on determining the source of the material and its method of production.

Nuclear forensics provides essential insights into methods of production and sources of illicit radioactive materials. It is most powerful when commed with traditional methods of investigation, including intelligence sources and traditional detective work. Nuclear forensics can play a decisive role in attributing and prosecuting crimes involving radioactive materials.

Some of the current limitations of nuclear forensics are a result of the emerging nature and increasing urgency of this discipline. For example, the world's nuclear powers are only now beginning to share information about their nuclear processes and materials. Numerous databases exist in many countries and organizations that could be valuable for the future development and application of nuclear forensics. The contents of many of these databases will never be directly shared, but the development of a "distributed" comprehensive database (see Section 6.3) will benefit international efforts. In addition, countries are beginning to combine the expertise of traditional forensics experts, normally found in police organizations, and nuclear experts, normally found in universities and government laboratories.

Nuclear forensics will always be limited by the diagnostic information inherent in the interdicted material. For example, the clever criminal can minimize or eliminate the important markers for traditional forensics (fingerprints, stray material, etc.). Some nuclear materials inherently have isotopic or chemical characteristics that serve as unequivocal markers of specific sources, production processes, or transit routes. Other nuclear materials do not. Fortunately, the international nuclear engineering enterprise has a restricted number of conspicuous process steps that makes the attribution process easier. Finally, it will always be difficult to distinguish between materials that reflect similar source or production histories, but are derived from disparate sites.

\subsection{On-going International Cooperation}

Many international forensics laboratories are already cooperating to develop common technical strategies and databases that catalog nuclear processes for use in nuclear attribution. The Nuclear Smuggling International Technical Working Group (ITWG) was formed in 1995 to foster international cooperation in combating illicit trafficking of nuclear materials. More than 28 nations and organizations have participated in seven international meetings and round-robin analytical trials to-date. Technical priorities for the ITWG include development of accepted and common protocols for the collection of evidence and laboratory investigations, prioritization of techniques and methods for forensic analyses for nuclear and non nuclear samples, interlaboratory forensic exercises, development of forensic databanks to assist in interpretation, and technical assistance for requesting countries. 


\subsection{TECDOC Structure}

The following discussion of nuclear forensics and attribution follows the general flow of the Model Action Plan developed by the Nuclear Smuggling International Technical Working Group (ITWG):

- Incident Response

- Laboratory Sampling \& Distribution

- Radioactive Material Analysis

- Traditional Forensic Analysis

- Case Development 


\section{MODEL ACTION PLAN - INCIDENT RESPONSE}

\subsection{Securing the Incident Site}

IAEA-TECDOC 1313 "Response to events involving the inadvertent movement or illicit trafficking of radioactive materials" provides detailed recommendations for the initial response to the interdiction of illicit nuclear material [12]. This document assumes the implementation of the recommendations of IAEA-TECDOC 1313.

There are 3 key goals to any response:

- Minimization of any radiological hazards associated with the incident site

- Control of the nuclear material

- Preservation of both nuclear and associated traditional forensic evidence

The Incident Commander must make decisions that involve the often-competing concerns of public safety, environmental protection, the safety of response personnel, and the preservation and collection of evidence. In order to understand the requirements of the nuclear forensics investigation, the Incident Commander should form an Incident Investigation Team at an early stage. The Incident Investigation Team should include experts in all of the relevant disciplines and provide advice and support to the Incident Commander. The Incident Investigation Team should include a person knowledgeable in nuclear forensics, if at all possible, or, if not, a law enforcement forensics specialist. The experts in the Incident Investigation Team will often reflect competing interests, so their consensus will provide the best balance between those interests. The Incident Commander can adjudicate any irresolvable disputes within the Incident Investigation Team.

From the standpoint of nuclear forensics, preservation of the evidence is vital. Therefore, it is extremely important to establish a protective cordon around the incident site as soon as possible in order to prevent unauthorized personnel from intentionally or unintentionally tampering with the evidence. The Incident Investigation Team must also protect the evidence from environmental factors, such as rain or high winds in an outdoor incident or turbulent ventilation in an indoor incident. The Incident Commander should sequence activities to minimize destruction or contamination of the evidence. For example, the legitimate goal of site decontamination should occur after the collection of evidence if at all possible. The collection of traditional forensics evidence should be performed in a manner that preserves the integrity of the nuclear forensics evidence and vice versa.

When the Incident Commander decides that evidence collection is safe and feasible, a photographer should make a thorough video or photographic record of the incident scene before entry. The photographic evidence should ensure a progression of overall, medium, and close-up views of the scene with an appropriate scale. All significant evidence should be photographed before removal from the scene. The use of electronic recording media (e.g., video recorders 
and/or digital cameras) is preferred and will facilitate the collection and dissemination of photo documentation.

Due consideration should also be given to the legal ramifications of evidence collection. For example, the Incident Commander should determine, with the necessary legal advice, whether a search warrant is needed for the evidence collection.

\subsection{On-site Analysis}

The collection of evidence assumes that any explosive device is first rendered-safe by appropriately qualified explosive ordinance disposal personnel. The availability of a fieldportable X-ray radiography device can expedite this process by allowing the imaging of solid samples and containers in the field to confirm the absence of "booby-traps" or other threats. Only after stabilization and release by explosive and weapons experts will access be provided for nuclear forensics and attribution.

In addition, on-site non-destructive analysis (NDA) using gamma-ray spectrometry can categorize the suspected radioactive material without affecting the evidence. The goal of categorization is to identify the bulk constituents of the material and to determine whether it is SNM, naturally occurring radioactive material, radioactively contaminated material, a commercial radioactive source, or nuclear reactor fuel.

The categorization analysis can be performed quickly and is essential for confirming the seized evidence as contraband. A very important outcome of the in-field categorization is the insight into the possible laws that have been broken, which forms the basis for the continued investigation. Therefore, a field-portable gamma-ray detector is an important piece of equipment for the Incident Investigation Team. Categorization can also provide important information for both the Radiological Safety Officer and the Incident Investigation Team.

Member States may request assistance from the INFL with operations and analysis at the incident site. The Member State can initiate contact with the INFL (see Option 1 in Appendix A) to evaluate the need for nuclear forensics assistance. In addition, the INFL can provide advice regarding such activities as collection and preservation of evidence and categorization of radioactive materials (see Option 2 in Appendix A). The INFL expert(s) can even serve as an adjunct to the Incident Investigation Team by providing remote consultation via telecommunications on nuclear forensics issues that arise.

\subsection{Collection of Radioactive Evidence}

The Radiological Safety Officer can help locate radioactive evidence at the incident site through use of the radiation monitors. The use of a grid system will aid in the radiological survey of the site and individual readings could be referenced to these squares. It is advisable to draw an accurate plan of the incident scene (including the compass orientation) that shows the location of any radioactive material or other evidence, the extent of the contamination, and the establishment 
of cordon and control areas. The use of the grid system can assist with the production of such a drawing. Photo documentation is advisable.

Radioactive evidence collection must be consistent with accepted radiological safety practices. Limiting time in the contaminated area and maximizing distance and shielding between the exposed personnel and radioactive sources can lessen the risk to the Incident Investigation Officers. The Radiological Safety Officer, equipped with personal dosimetry and radiation detection survey equipment, will determine the maximum time that any Incident Investigation Officer can spend around the nuclear material based upon the type and level of the radioactivity and applicable health limits governing radiation exposure. In extreme cases, it may be necessary to collect the radioactive evidence using timed shifts of Incident Investigation Officers or even unmanned robots.

The Radiological Safety Officer will also specify and provide appropriate personal protective equipment (PPE). As appropriate, Incident Investigation Officers should use rubber gloves, safety goggles, and an approved respirator, when collecting radioactive evidence. In addition, disposable overalls and overshoes may be appropriate to eliminate contamination of personal clothing. All PPE must be decontaminated or disposed of as radiological waste when done.

If the radioactive evidence is well-contained, for example, LEU powder inside a lead "pig", the investigating officials should only secure the sample and remove it from the scene with due attention to preserving any traditional forensic evidence. On the other hand, if the evidence is widespread or scattered, the investigating officials must take care to be as comprehensive as possible in the collection. It is hard to predict a priori, what portion of the evidence might prove to be critical to the attribution.

The Incident Investigation Officers should also take as much care as is reasonable, given the tools at hand and time limits due to radiation levels, to extricate the radioactive material from non-radioactive material (local dirt, grass, or leaves) and evidence. If there is any doubt as to what is evidence and what is contamination, Incident Investigation Officers should err on the side of being comprehensive and collecting too much material, rather than not enough.

The Incident Investigation Officers can scoop solid samples into clean plastic bags using a spatula or shovel. If there appears to be several types of material, located in different areas, then, if practical, the Incident Investigation Officer should try to minimize cross-contamination by using a different spatula or shovel to collect each type of material or, at least, to clean the spatula or shovel between samplings. All plastic bags must be appropriately labeled with their contents and the appropriate reference designator.

Radioactive liquid samples can be collected in clean plastic bottles. The Incident Investigation Officers can use syringes or pipettes to transfer the liquid from the scene into the jars. If there appears to be several types of liquids, then, if possible, the Incident Investigation Officer should try to minimize cross-contamination by using a different syringe or pipette to collect each liquid or, at least, to clean the syringe or pipette between samplings. Extremely large volumes of liquid may need to be collected using an industrial wet vacuum. The vacuum would then require decontamination when finished. All bottles must be appropriately labeled with their contents and 
appropriate reference designator. Collection apparatus, including spatulas and syringes, must be decontaminated or disposed of as radioactive waste.

The initial plastic containers should be sufficient to contain and transport radioactive samples that are only alpha or beta emitters. If the samples are gamma ray emitters, however, the Radiological Safety Officer may require that the sample containers be transported inside a leadlined container or "pig."

If immovable or large objects, such as buildings or cars, have become contaminated with radioactive evidence, then it will be necessary for the Incident Investigation Officer to "swipe" these objects. A swipe is a filter material usually made out of synthetic fibers and is a convenient method for collecting particulate samples. Sticky tape can also be used to collect particulate from the surface of objects. The Incident Investigation Officers should attempt to swipe as large an area as possible to remove all of the radioactive evidence. A fresh swipe or sticky tape should be used to sample new objects. When finished, each swipe should be placed in its own plastic bag and appropriately labeled.

The collection of radioactive samples by swiping may destroy traditional forensic evidence, such as fingerprints. Therefore, it is essential that appropriate thought be given to the relative timing of the collection of radioactive evidence relative to traditional forensic evidence. The ultimate decision rests with the Incident Commander with input from the Incident Investigation Team.

The Incident Investigation Officers must maintain appropriate chain-of-custody procedures during the evidence collection process. In particular, each sample container (plastic bag or bottle) must be labeled with a unique designator. The evidence recovery log must tie the designator to a particular location on the incident site, as well as to the particulars of the collection method. The nuclear forensic laboratory will then maintain chain-of-custody paperwork that will tie the analytical results and conclusions to that unique designator. All evidence must be supervised and protected while awaiting transportation from the incident scene.

\subsection{Collection of Traditional Forensic Evidence}

Again, it is advisable to draw an accurate plan, including the compass orientation, of the incident scene that shows the location of any radioactive material or other evidence, the extent of the contamination, and the establishment of cordon and control areas. The use of the grid system can assist with the production of such a drawing. This plan could become an essential item of information in a judicial process. Photo documentation is again advisable.

The collection of traditional forensic evidence must be consistent with good radiological safety practice. The traditional forensic evidence is frequently commingled with the radioactive evidence. The risk to the Incident Investigation Officer can be minimized through the principles of time, distance, and shielding as described earlier.

As the Incident Investigation Team approaches the incident scene, they should be alert for any discarded evidence. They should make pertinent notes as they survey and take control of the 
scene. With the help of the Radiological Safety Officer, they should continually assess the safety of all operations. The team should determine the extent to which the incident scene has been protected so far and be alert for any signs of tampering with the evidence.

The Incident Investigation Team should first initiate a preliminary survey that should delineate the extent of the search area, note any physical or environmental constraints bearing on the collection of evidence, and obtain information necessary to organize the detailed search.

A full forensic search of the scene should be conducted, if possible. If a grid system is implemented, then a systematic search of each square may uncover relevant forensic evidence. All evidence associated with the radioactive sample, such as the original sample container, associated paperwork, etc., must be collected. Such evidence is often important for the purposes of attribution and may constitute the only evidence as to the path of the sample from loss of control until interdiction.

The collection of traditional forensic evidence might interfere with the collection or analysis of radioactive evidence. Therefore, it is essential that appropriate thought be given to the relative timing of the collection of radioactive evidence versus traditional forensic evidence. The ultimate decision rests with the Incident Commander with input from the Incident Investigation Team.

As with the collection of radioactive evidence, the Incident Investigation Officers must maintain appropriate chain-of-custody procedures during the evidence collection process. This includes the logging of all samples into the evidence recovery log. In addition, all evidence must be supervised and protected while awaiting transportation from the incident scene.

\subsection{Final Survey \& Release of Scene}

The Incident Investigation Team should conduct a final survey before releasing the crime scene to the proper authorities. In the final survey, all participants should critically review all aspects of the search to ensure completeness. They should make sure that any potential hiding places or difficult to access areas have not been overlooked.

The documentation should also be checked for inadvertent errors or omissions. The photographer should document the final condition of the incident scene. All evidence should be accounted for before departing the scene. Finally, the team should gather all of the equipment used in the search.

When the final survey is complete, the Incident Commander can release the crime scene to the proper authorities. This release should be documented, including date, time, to whom the scene was released, and who released it. The scene should not be released until the Incident Investigation Team is ready, because, once a scene is released, re-entry may require a warrant. 


\subsection{Evidence Holding Site}

Depending on local regulations and the procedures of the nuclear forensics laboratory, it may be necessary to store the evidence after collection and before ultimate transport to the nuclear forensics laboratory. Therefore, it may be necessary to establish an intermediate storage facility or "holding site." This facility must have the security necessary to store the evidence and the radiological permits necessary to handle the level of radioactivity present in the samples. Member States can request INFL assistance with the establishment and operation of the holding site (see Option 2 in Appendix A).

Solid evidence, e.g., closed containers, should once again be imaged using X-ray radiography at the holding site to understand the nature of the evidence and confirm the absence "booby-traps" or other threats. If material categorization was not performed at the incident site, it should definitely be performed at the holding site before transportation to the nuclear forensics laboratory. Even if material categorization was performed at the incident site, it may be useful to confirm the categorization, perhaps using more advanced instrumentation, e.g., gamma-ray spectrometry with a high-resolution germanium detector rather than a sodium iodide detector. The additional categorization could provide additional information, as well as an evaluation of the efficacy of the on-site categorization. The Member State can request advice from the INFL regarding categorization of radioactive materials (see Option 2 in Appendix A).

\subsection{Evidence Transportation}

In transporting evidence, either to the intermediate storage facility or the nuclear forensics laboratory, the Incident Investigation Officers must consider safety, security, and preservation of evidence. Most samples can be kept in their collection containers for shipment. However, these primary containers must be packed inside another container certified for the shipment of such material. In all cases, the packaging procedures must satisfy legal and safety requirements. Licensed and authorized carriers should be used to transport the material whenever possible.

The Incident Investigation Officers should make certain that all containers are properly sealed and that the external packaging is sturdy enough to protect the inner containers from being accidentally breached. This is important not only from a safety perspective, but also to ensure that the evidence is not compromised by contamination or cross-contamination during shipment. It is also important to ensure that the shipping container has not become contaminated with radioactive material and that the radiation measured outside the container is within acceptable levels.

Security for the samples can also be an important concern. By its very nature, radioactive evidence may be targeted for diversion. It is not inconceivable that desperate groups may try to regain control of the material by force during transport. For this reason, protection and accounting is paramount.

If the evidence is shipped to a laboratory within the country of seizure, then the Incident Investigation Officers must ensure that the shipment of the evidence complies with national laws 
regarding the shipment of radioactive material and SNM, if applicable. If the evidence is shipped outside the country of seizure, the Incident Investigation Officers must ensure that the shipment of the evidence complies with laws regarding exporting such material from the country of seizure and the importing such material from the country of analysis.

Member States may also request assistance from the INFL with transportation of radioactive materials from the incident site or holding site to the nuclear forensics laboratory (see Option 3 in Appendix A). The INFL can, in consultation with the IAEA, provide advice regarding packaging and transportation to meet legal requirements and to prevent contamination or crosscontamination of evidence. 


\section{MODEL ACTION PLAN - LABORATORY SAMPLING \& DISTRIBUTION}

\subsection{The Nuclear Analysis Laboratory}

The evidence should be sent for analysis at a laboratory equipped to receive and process such samples. It may be possible to send the traditional forensic evidence to a police crime lab and the nuclear forensic evidence to a nuclear analysis laboratory. However, it is highly likely that the two types of evidence are commingled, that is, that the traditional forensic evidence is contaminated with radioactive material and that the radioactive material contains some forensic evidence. Therefore, the receiving laboratory should be able to handle radioactive material and carefully separate the traditional forensic evidence from the radioactive material for later analysis by experts in each discipline. Consequently, it is advisable to send the sample to a laboratory skilled in nuclear forensics analysis that combines the capabilities of the crime lab and the nuclear analysis laboratory. Nuclear forensics laboratories are outfitted and staffed to handle contaminated evidence and accommodate the requirements of both the traditional forensics and nuclear analysis.

The nuclear analysis laboratory should be an appropriately accredited and recognized facility with analytical procedures and staff qualifications that are documented and can withstand both scientific peer-review and legal scrutiny. In addition, the laboratory must be appropriately licensed to receive the evidence being shipped. The receival facility must be able to handle large amounts of nuclear materials, yet still be able to analyze trace levels of the material constituents and environmental types of materials. Consequently, as part of its design, the laboratory must be free from fixed and dispersible background contamination and ensure that there is no chance of cross-contamination between samples.

The nuclear analysis laboratory should be fully qualified to current standards in environmental, safety, and health protocols, hazardous waste disposal procedures, and hazardous materials handling and storage. The nuclear analysis laboratory should be intimately familiar with the requirements of a legal investigation, including the ability to perpetuate the sample chain-ofcustody that began in the field.

Staff experts at the nuclear analysis laboratory should be able to provide varying levels of response, depending on the requirements of the interdicting authorities. This might involve just consultation or increasing levels of data acquisition and analysis ranging from basic characterization to a full nuclear attribution.

Member States may also request assistance from the INFL with the nuclear forensics analysis. The INFL can identify an appropriate member laboratory to provide assistance (see Option 4 in Appendix A) and to determine the level of effort required (basic characterization versus full attribution). The actual investigation will be carried out on a state-to-state basis and will require a bilateral agreement. The INFL laboratory will work with the Member State to develop an 
appropriate statement of work (SOW) for the nuclear forensics analysis (see Option 5 in Appendix A). The SOW will establish the requirements of the Member State, including rules of evidence, sharing of information, non-disclosure agreements, etc. The SOW will also establish expectations about timelines and the frequency and type of communication. The SOW will form the basis of the state-to-state agreement.

\subsection{The Forensic Management Team}

A Forensic Management Team (FMT) should be established before any nuclear forensic or traditional forensic analysis is performed. The FMT should be largely populated with nuclear forensic experts, but also the appropriate law enforcement and state officials. In the case where a Member State requests assistance from the INFL, the FMT would be established upon finalizing the SOW, which will govern the laboratory analysis of the evidence. In this case, the FMT would include the nuclear forensics experts at all participating laboratories, as well as law enforcement and state officials from the requesting Member State.

\subsection{Sampling and Aliquoting in the Nuclear Forensics Laboratory}

The FMT should develop the initial experimental plan. The experimental plan should include methods for preventing contamination or cross-contamination of the evidence. Because of the dynamic nature of the forensics process, the FMT will modify the experimental plan as new information about the sample or the investigation is obtained.

The experimental plan must not assume the nuclear material is homogeneous or that the materials from different samplings throughout the incident site are identical. Consequently, a single bulk analysis may not be appropriate to fully categorize, characterize, or attribute the sample. The laboratory must establish good sampling techniques to adequately characterize the radioactive evidence. In the extreme, this could mean analysis of individual particles, but, more commonly, would mean separate bulk analyses for each individual components of the radioactive evidence.

When the amount of material being sampled is small, the experimental plan must allocate the limited amount of sample. In this case, it is important that all non-destructive analyses be performed first. In addition, trace and microanalytical techniques are more appropriate than techniques that require large amounts of material.

Solid evidence, e.g., closed containers, should be imaged using X-ray radiography before sampling in the laboratory to understand the nature of the evidence and confirm the absence "booby-traps" or other threats to examiners. Assuming that the X-ray analysis shows no danger, then the sampling can proceed.

It is once again useful to categorize the material. The additional categorization could provide new information, as well as an evaluation of the efficacy of the on-site and holding site categorizations. High-resolution gamma-ray spectrometry and isotope ratio mass spectrometry 
are essential for the categorization at the nuclear forensic laboratory. For bulk samples, isotope ratio mass spectrometry can be performed using either thermal ionization mass spectrometry (TIMS) or inductively coupled plasma mass spectrometry (ICP-MS). 


\section{MODEL ACTION PLAN- RADIOACTIVE MATERIALS ANALYSIS}

\subsection{Overview}

Nuclear forensics does not incorporate routine procedures that can be universally applied to all evidence. Rather, it involves an iterative approach, in which the results from one analysis are used to guide the selection of subsequent analyses. In this way, radioactive materials analysis applied to nuclear forensics proceeds in a manner not unlike that of traditional forensic analysis.

It is important to emphasize that all sampling and analysis must be performed with due regard for preservation of evidence. The sampling process can equally extract and obliterate evidence. Many of the analytical tools used in radioactive materials analysis are destructive, that is, they consume some amount of sample during analysis. Therefore, the proper selection and sequencing of analyses is critical.

Further analysis will be guided by the initial categorization. The FMT must choose the next analysis based upon the ultimate goals of the investigation (basic characterization versus full attribution - see below), the information uncovered so far, the potential signatures (physical, chemical, elemental, isotopic) that might lead to precise attribution, the amount of sample available for analysis, and methods for measuring forensic signatures.

\subsection{Basic Characterization}

The goal of basic characterization is to determine the nature of the radioactive evidence. Basic characterization provides full elemental analysis of the radioactive material, including major, minor, and trace constituents. For those major constituents of the radioactive material, basic characterization would also include isotopic and phase (i.e., molecular) analysis, if necessary. Basic characterization would not include analysis of traditional forensic signatures or reactor modeling and database searches to identify probable sources of the material.

Basic characterization does include physical characterization. The sample should be imaged at high magnification, by a scanning electron microscope, for example. The critical dimensions of solid samples and the particle size and shape distributions of powder samples should be measured.

The basic characterization will take less time than the full attribution. The length of the process will depend on the laboratory's workload, but could be completed within 2 to 4 weeks after receipt of the samples. 


\subsection{Full Attribution}

The goal of full attribution is to analyze all radioactive and traditional forensic evidence in order to attribute the nuclear material, including its origin, method of production, probability that more of the material exists, transit route, and means by which administrative control over the material was lost. This includes the analysis of the traditional forensic evidence and comprehensive analysis of the radioactive evidence. Full attribution analysis would include reactor modeling and/or database searches to identify the method of manufacture and probable sources of the material.

Data interpretation is the crucial factor in successfully attributing material based upon analyses conducted in the nuclear forensics laboratory. Data interpretation includes the ability to match analytical data with existing information on sources and methods used to produce radioactive materials and with prior cases involving smuggled and interdicted nuclear materials. While analytical protocols have improved systematically with advances in technology, the ability to interpret radiochemical data for the purposes of attribution has not progressed equally. The challenge for the future is to develop and apply tools for data interpretation that provide combined and credible determinations of locations and methods of materials production.

\subsection{Summary of Available Tools}

The nuclear forensic scientist has a wide array of analytical tools to use for detecting signatures in radioactive material. Appendix B provides a listing and description of many of the techniques used in radioactive material analysis. These individual techniques can be sorted into three broad categories: bulk analysis tools, imaging tools, and microanalysis tools.

Bulk analysis tools allow the forensic scientist to characterize the elemental and isotopic composition of the radioactive material as a whole. In some cases, bulk analysis is necessary to have sufficient material to adequately detect and quantify trace constituents. The presence and concentration of trace constituents are often vitally important as signatures for certain manufacturing processes, for determining the time since chemical separation, and for determining whether the material has been exposed to a neutron flux.

Imaging tools provide high magnification images or maps of the material and can confirm sample homogeneity or heterogeneity. Because bulk analysis provides an integrated compositional measurement of the sample as a whole, if the material is inhomogeneous, the resulting analysis could obscure important signatures in the individual components. Imaging will capture the spatial and textural heterogeneities vital to fully characterize a sample.

If imaging analysis confirms that the sample is heterogeneous, then microanalysis tools can quantitatvely or semi -quantitatively characterize the individual constituents of the bulk material. The category of microanalysis tools also includes surface analysis tools, which can detect trace surface contaminants or measure the composition of thin layers or coatings, which could be import for attribution,. 


\subsection{Sequencing of Techniques \& Methods}

The international nuclear forensics community, as represented in the ITWG, has achieved a general consensus on the proper sequencing of techniques so as to provide the most valuable information as early as possible in the attribution process. This consensus was achieved through discussion and consultation at regular meetings, as well as from experience developed from two round robin analyses by INFL laboratories. Table 2 shows the generally accepted sequence of analysis, broken down into techniques that should be performed within 24 hours, 1 week, or 2 months.

Table 2

Sequence for Techniques/Methods

\begin{tabular}{|c|c|c|c|}
\hline Techniques/Methods & 24-Hour & 1-Week & 2-Month \\
\hline Radiological & $\begin{array}{l}\text { Estimated total activity } \\
\text { Dose Rate }(\alpha, \gamma, \mathrm{n}) \\
\text { Surface Contamination }\end{array}$ & & \\
\hline $\begin{array}{l}\text { Physical } \\
\text { Characterization }\end{array}$ & $\begin{array}{l}\text { Visual Inspection } \\
\text { Radiography } \\
\text { Photography } \\
\text { Weight } \\
\text { Dimension } \\
\text { Optical Microscopy } \\
\text { Density }\end{array}$ & $\begin{array}{l}\text { SEM (EDX) } \\
\text { XRD }\end{array}$ & TEM (EDX) \\
\hline $\begin{array}{l}\text { Traditional Forensic } \\
\text { Analysis }\end{array}$ & Fingerprints, Fibers & & \\
\hline Isotope Analysis & $\begin{array}{l}\gamma \text {-spectroscopy } \\
\alpha \text {-spectroscopy }\end{array}$ & $\begin{array}{l}\text { Mass spectrometry } \\
\text { (SIMS, TIMS, } \\
\text { MC-ICP-MS) }\end{array}$ & $\begin{array}{l}\text { Radiochemical } \\
\text { separations }\end{array}$ \\
\hline Elemental/Chemical & & $\begin{array}{l}\text { ICP-MS } \\
\text { XRF } \\
\text { Assay (titration, IDMS) }\end{array}$ & GC/MS \\
\hline
\end{tabular}




\section{MODEL ACTION PLAN- TRADITIONAL FORENSIC ANALYSIS}

\subsection{Overview}

Traditional forensic analysis, like radioactive materials analysis, is an iterative process, in which the results from one analysis are used to guide the selection of subsequent analyses. The forensic analyst must carefully examine all of the items seized at the incident site in order to uncover as much information as possible. Unlikely and apparently unrelated evidence often are key to the successful prosecution of a case.

Once again, all sampling and analysis must be performed with due regard for preservation of evidence. The sampling process could contaminate or destroy some evidence while pursuing other evidence. The collection of traditional forensic evidence on radioactively contaminated materials must also be performed in a manner consistent with good radiological safety practice.

\subsection{Summary of Available Tools}

The variety of traditional forensic evidence, as well as the methods of collection and evaluation, is almost limitless. Appendix $\mathrm{C}$ provides a representative, but not exhaustive, summary of traditional forensic evidence. For example, evidence such as tissue, hair, fingerprints, and shoeprints can often associate a specific individual with a specific place or object. The analysis of fibers, pollen, or chemical substances found at the incident scene can provide information about motives or transportation routes. Documentary evidence provides useful information not only in the content of the communication itself, but also in the incidental details of its creation (paper, ink, film type, extraneous noises, accents).

\subsection{Sequencing of Techniques \& Methods}

Similar to collection of radioactive evidence, the international community has agreed upon a sequence for traditional evidence collection. Table 2 shows that the collection of fingerprint and fiber evidence must occur within the first 24 hours after sample receipt. The chemical analysis of other evidence by techniques, such as gas chromatography/mass spectrometry (GC/MS), may occur up to two months after the recovery of evidence. 


\section{MODEL ACTION PLAN - CASE DEVELOPMENT}

\subsection{Relevant Signatures}

Signatures are the characteristics of a given nuclear or radiological material that enable one to distinguish that material from other nuclear or radiological materials. These signatures enable one to identify the processes that created the material, aspects of the subsequent history of the material, and potentially the specific locales in the history of the material. Much of the research and development in nuclear attribution centers on the understanding and discovery of these signatures. Two important approaches to delineating signatures are: 1) discovery using an empirical approach through the systematic analysis of nuclear and radiological materials, and 2) modeling based on the chemistry and physics of nuclear processes. Signatures include physical, chemical, elemental, and isotopic characteristics of the material.

Physical characteristics of the material include the texture, size, and shape of solid objects and the particle size distribution of powder samples. For example, the dimensions of a fresh nuclear fuel pellet are often unique to a given manufacturer. The particle size distribution of uranium oxide powder can provide evidence about the uranium conversion process. Even the morphology of the particles themselves, including such anomalies as inclusions or occlusions, can be indicative of the manufacturing process.

Chemical characteristics of the material include the exact chemical composition of the material or the association of unique molecular components. For example, uranium oxide can be found in many different forms, e.g., $\mathrm{UO}_{2}, \mathrm{U}_{3} \mathrm{O}_{8}$, or $\mathrm{UO}_{3}$, each of which can be found at various points in the uranium fuel cycle. The association of some organic compounds, such as certain light kerosene oils or tributyl phosphate, with the nuclear material can be indicative of a reprocessing operation.

Elemental signatures of the material include the determination of major, minor, and trace elements in the material. Major elements, of course, help define the identity of the nuclear material, but minor elements, such as erbium or gadolinium that serve as burnable poisons or Ga that serves as a phase stabilizer for $\mathrm{Pu}$, also help define its function. Trace elements can also prove to be indicative of a process, e.g., $\mathrm{Fe}$ and $\mathrm{Cr}$ residues from stainless steel tooling or $\mathrm{Ca}$, $\mathrm{Mg}$, or $\mathrm{Cl}$ residues from a water-based cleaning process.

Isotopic signatures of the material include the detection of fission or neutron-capture products, which are indisputable evidence that the material has been in a nuclear reactor and serves as a fingerprint for the type and operating conditions of a given reactor. Other isotopes are decay products from radioactive "parent" isotopes in the material. For example, ${ }^{230} \mathrm{Th}$ is a decay product of ${ }^{234} \mathrm{U}$ and ${ }^{235} \mathrm{U}$ is a decay product of ${ }^{239} \mathrm{Pu}$. Because radioactive isotopes decay at a rate determined by the amount of the isotope in the material and the half-life of the parent isotope, one can use the relative amounts of decay products and parent isotopes to determine the "age" of the material (time since the parent isotope was last chemically separated from its decay products). 
Table 3 lists some of the relevant signatures in a $\mathrm{Pu}$ sample and what those signatures might reveal.

Table 3

Relevant Signatures in Plutonium

\begin{tabular}{|l|l|}
\hline Signature & Information Revealed \\
\hline In-growth of daughter isotopes & Chemical processing date \\
\hline $\mathrm{Pu}$ isotope ratios & $\begin{array}{l}\text { Enrichment of U used in Pu production } \\
\text { Neutron spectrum in production reactor }\end{array}$ \\
\hline Residual isotopes & Chemical processing techniques \\
\hline $\begin{array}{l}\text { Concentration of short-lived fission } \\
\text { product progeny }\end{array}$ & Chemical yield indicators \\
\hline $\mathrm{Kr}$ and Xe concentration & Casting time \\
\hline
\end{tabular}

\subsection{Cooperation with Other Nuclear Forensics Laboratories}

Experience from prior attribution cases is one key source of knowledge about possible nuclear sources and processes. Access to knowledge from the broadest collection of experts possible increases the chances of a unique and successful attribution. Consequently, the attribution process can only be helped by allowing access to the combined experience of nuclear forensic laboratories throughout the world. The sharing of information between international nuclear forensics laboratories, consistent with non-disclosure requirements specified in the SOW, leverages the extensive experience and newly developed capabilities of each laboratory to develop new and valuable information about the smuggling effort, route location, and the source of the material. The participation of other nuclear forensics laboratories also allows for a peer review of the nuclear attribution process, increasing confidence in the validity and impartiality of the attribution effort. It is, therefore, highly recommended that the Statement of Work (see Option 5 in Appendix A) include the approval for the responsible nuclear forensics laboratory to share information with one or more of the other forensics laboratories around the world.

\subsection{Knowledge Bases of Nuclear Processes}

Clearly, an extensive knowledge base of nuclear processes is necessary for effective nuclear attribution. Forensic databases are essential for successfully applying analytical data to existing information on the sources, methods, and origin of nuclear materials throughout the world. This ability to compare signatures with existing knowledge and data is at the heart of case development.

Knowledge and databases are presently maintained by international, national, and nongovernmental entities. Through efforts such as those led by the ITWG, there are currently efforts to develop and organize databases that catalog nuclear processes for use in nuclear forensics and attribution. 
In some cases, these databases contain components that can be freely shared among the participants, as well as components that contain proprietary information to which access is restricted. Experts from each participating country or organization, as part of a worldwide network, maintain access to their own databases and knowledge bases to which they have full access. In response to queries for information from other experts in the network, they can respond by releasing the results of the queries without compromise of any of the restricted information or data that underlie the response. Thus distributed data can be used to create information for the network with due consideration for data security.

\subsubsection{Archived samples}

Comparative analyses of interdicted material and archived samples can also be particularly helpful. These analyses allow the nuclear forensic expert to establish connections between the interdicted material and archived material or between the processes used to create them. As new signatures are discovered that depend on new analytical methods, it becomes increasingly important that archived data be accompanied by archived material. Then, the old material can be re-analyzed by the new analytical methods and the resulting data analyzed for the presence or absence of the newly discovered signatures. Sample archives can include "real world" attribution samples, reactor fuel stock, SNM, and industrial radiological sources.

\subsubsection{Open literature}

Many of the basic nuclear processes are documented in textbooks, reports, and papers in the open literature. These documents can be found in technical libraries, as well as the World Wide Web. The IAEA web-site (http://www.iaea.org/), for example, has a number of databases that document publicly available information about nuclear facilities around the world.

\subsubsection{Closed literature}

Proprietary or classified processes may only be documented in the so-called "closed" literature. Companiesare often willing to share proprietary information with national nuclear forensics laboratories after the execution of an appropriate non-disclosure agreement. In addition, national laboratories are usually able to access the classified literature of their own country, but obviously not those of other countries. This makes international cooperation between nuclear forensics laboratories of vital importance to solving certain cases. 


\subsubsection{International cooperation}

As noted in section 1.8, international collaboration is essential to the world-wide problem of nuclear smuggling. By its very nature the smuggling enterprise is dynamic and itinerant - with nuclear material sourced in one site and transported to another. The ability to share some of the details of specific nuclear smuggling cases, unique analytical capabilities, and knowledge databases is important for countering the smuggling threat.

\subsection{An Iterative Process}

Analytical results from both radioactive materials analysis and traditional forensic analysis should be interpreted by experts representing a spectrum of all forensic and attribution specialties. Results from radioactive materials analysis and traditional forensics analysis guide the development of the nuclear forensics case. Nuclear forensic experts use both an empirical approach, through the previous analysis of nuclear and radiological materials, and a modeling approach, based upon the chemistry and physics of nuclear processes to predict relevant signatures from those processes. They also use their knowledge of analytical science to select the appropriate methods to verify the presence or absence of these signatures.

At the beginning of the nuclear forensics process, the results from the radioactive materials analysis and traditional forensic analysis will most likely be consistent with many attribution scenarios. As the process continues and new results prove inconsistent with those scenarios, certain attribution scenarios are excluded. In the optimum case, only a single scenario will eventually prove consistent with all results.

Case development is very much a deductive process (see Figure 1). The nuclear forensic expert develops a hypothesis or set of hypotheses based upon the results at that point. This hypothesis suggests additional signatures, which either might or must be present if the hypothesis is true. For example, Table 4 lists some of the chemical and isotopic markers characteristic of reprocessed reactor fuel. The expert then devises tests to verify the presence or absence of the signatures. Access to other experts around the world, to forensics knowledge bases, and to archived sample libraries are important tools that allow the nuclear forensics expert to formulate the hypothesis and the method to test it. If these tests show that the signature is absent, then the nuclear forensic scientist must abandon or adjust his hypothesis to fit the new results. If the tests show that the signature is present, then either a unique attribution has been achieved or additional tests must be devised to exclude the other possible attribution scenarios. 
Table 4

Reprocessed Reactor Fuel

Radiological and Chemical Signatures

\begin{tabular}{|l|}
\hline Tributyl phosphate (TBP) and its degradation products \\
\hline Odorless kerosene \\
\hline${ }^{85} \mathrm{Kr}$ \\
\hline${ }^{133} \mathrm{Xe}$ \\
\hline${ }^{129} \mathrm{I}$ \\
\hline Tritium $\left({ }^{3} \mathrm{H}\right)$ \\
\hline${ }^{134} \mathrm{Cs}$ or ${ }^{137} \mathrm{Cs}$ \\
\hline${ }^{106} \mathrm{Ru}$ \\
\hline${ }^{90} \mathrm{Sr}$ \\
\hline${ }^{99} \mathrm{Tc}$ \\
\hline Traces of $\mathrm{Pu}$ \\
\hline${ }^{241} \mathrm{Am}$ \\
\hline
\end{tabular}

The ongoing results of the analysis provide guidance and leads, aiding the police investigation by focusing their efforts. The more focused police investigation may then uncover further evidence that can be used to link the material to particular people or places, aiding the attribution process.

Some results, such as isotopic analysis, may only provide general clues that serve to place the material in a broad category like SNM or, perhaps narrow the field of potential countries of origin. Other results, such as the identification of characteristic dimensions or markings, may provide specific clues to identify a specific facility or date of manufacture. Sometimes, a result might only provide useful information about the attribution when combined with other results. In the same way, independent results that provide the same general or specific clue increases the expert's confidence in the attribution, while results that provide different or even conflicting results decrease this confidence. Nevertheless, a result that seems confusing or insignificant at first may become crucial as the case develops.

All interpretations must follow the rules of evidence appropriate to the jurisdiction of the case. In the United States, for example, the interpretations must meet the criteria of the Daubert standard, which allows for the introduction of theory or techniques that have been generally accepted in the particular scientific field during a trial. 


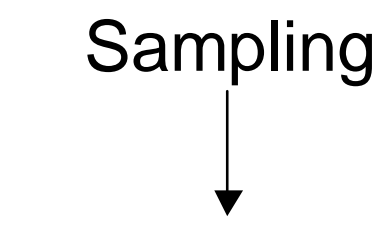

Categorization

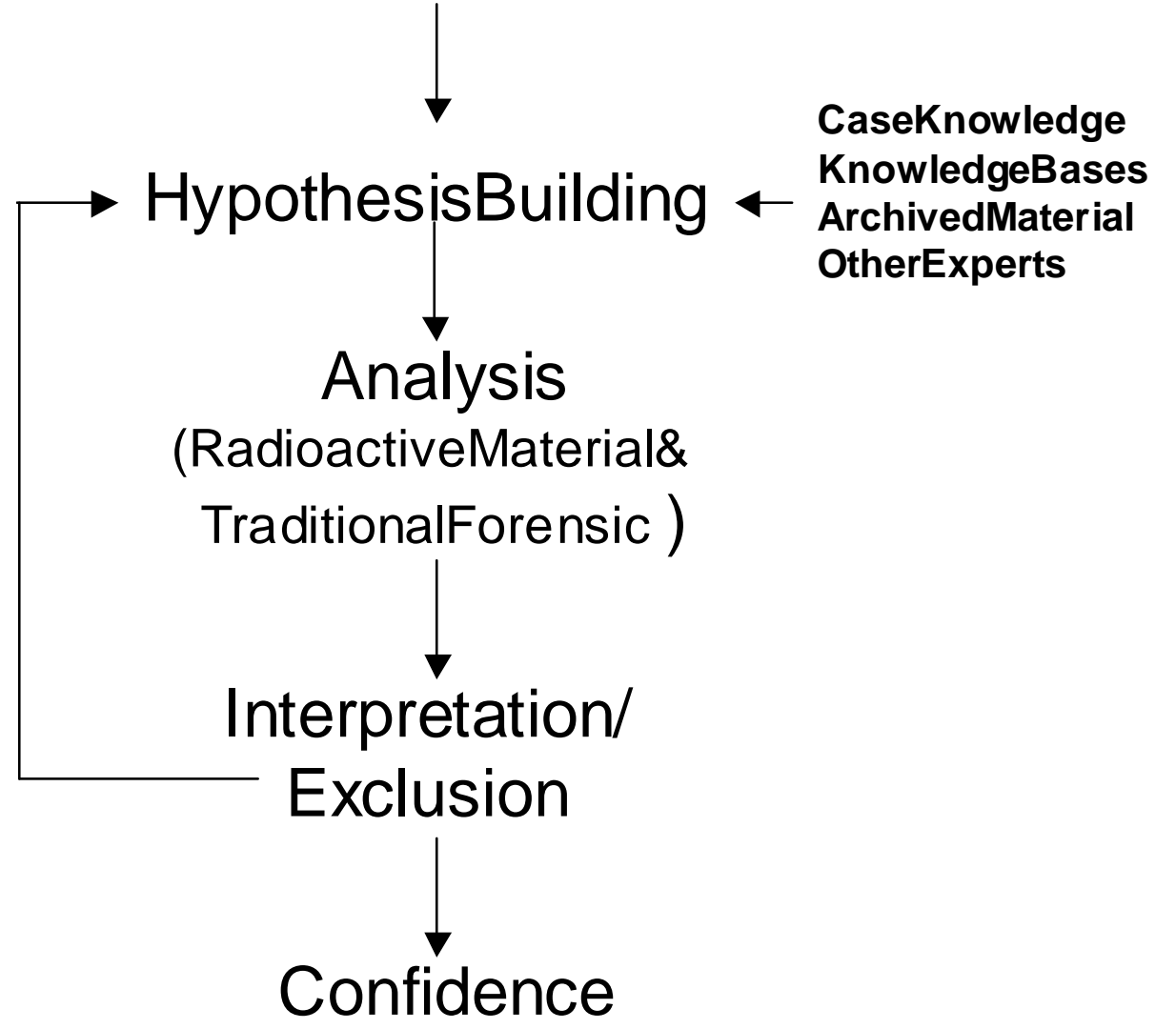

Figure 1

Flow Chart of Attribution Process 


\section{Nuclear Forensics and Smuggling Scenario}

\subsection{Hypothetical Example}

To better illustrate the process and complexities of nuclear forensics and attribution, Appendix D provides a fictious example of a case involving the discovery of illicit nuclear material and the subsequent steps, drawn from the ITWG Model Action Plan, to attribute the origin of this material and develop evidence for prosecution. While the case is hypothetical, it incorporates data and circumstances from actual nuclear smuggling experience. This worked example is designed to emphasize the steps required in an attributions response, as well as capabilities available as options to elucidate the nature of the smuggling enterprise and identify those responsible. It should be emphasized that the purpose of the example is to describe the approach to nuclear forensics and attributions; the specific response to an actual event will vary and depend on specific case circumstances. 


\section{Attribution Confidence}

\subsection{Analytical Data Quality Objectives}

Because the results of the attribution evaluation could be used as evidence in a criminal prosecution or affect international estimates of proliferation and threats of terrorism, it is essential that the data and its interpretation is credible. Adherence to chain-of-custody procedures will ensure that the analytical results correspond to evidence collected at the incident site. Proper quality assurance and quality control procedures within the nuclear forensics laboratory will ensure confidence in the analytical data.

Nuclear forensic laboratories should consider the implementation of a quality system, such as ISO 9000 [13] or ISO 17025 [14]. A quality system encourages the establishment of documented procedures for sample control and analysis, which improve repeatability of results and provide an enabling mechanism for continuous quality improvement. The establishment and registration of a quality system is important not only for its internal benefits, but also for the confidence that it inspires externally.

As part of the quality control system, laboratories should also place their analytical instruments under a relevant statistical process control (SPC) program wherever feasible. A valid SPC program engenders confidence in the analytical results by demonstrating that the instrument was under statistical control before and after the acquisition of data.

\subsection{Precision \& Accuracy}

As required by good analytical protocol, all analytical results should state the precision of the measurement and any potential sources of error not reflected in the precision. In the absence of bias, the precision of the measurement can place bounds on which sources and processes could produce material with the given signature.

Although increasing the precision of a given measurement could narrow the field of potential sources or processes that produced the material as shown in Figure 2, it is often more efficient to perform additional measurements using independent techniques (techniques that verify the presence or absence of different signatures than the initial technique). The confidence in, and the specificity of, the interpretation often increase as more independent measurements are made as shown in Figure 3. 


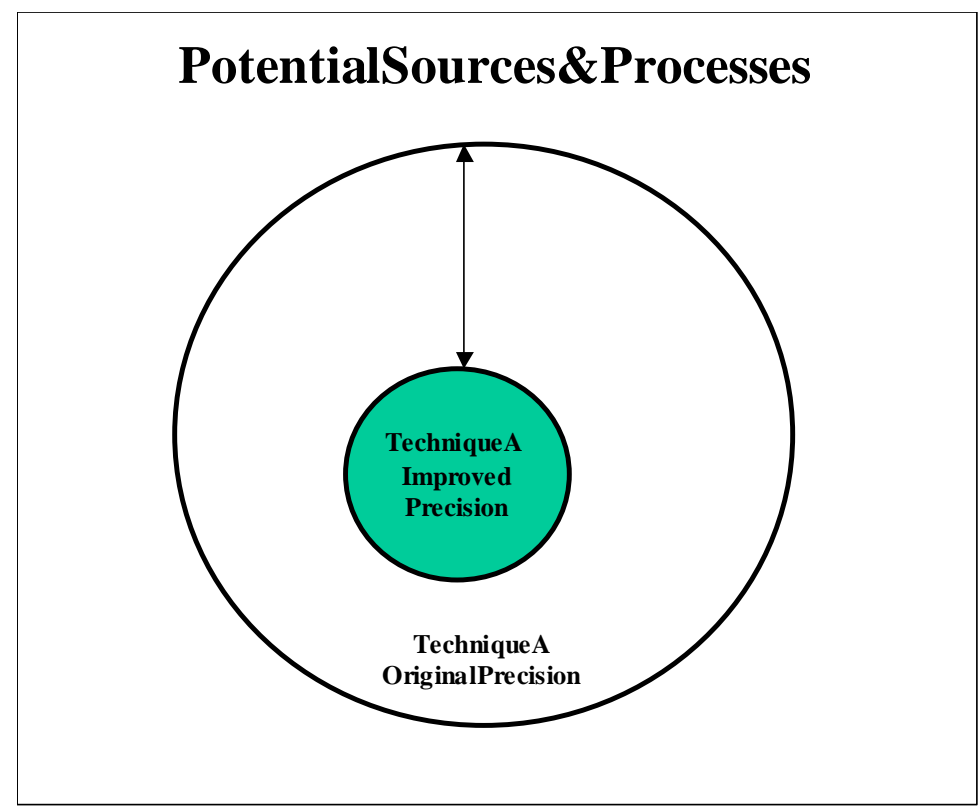

Figure 2

The Effect of Improved Precision on Attribution

Potential Sources \& Processes

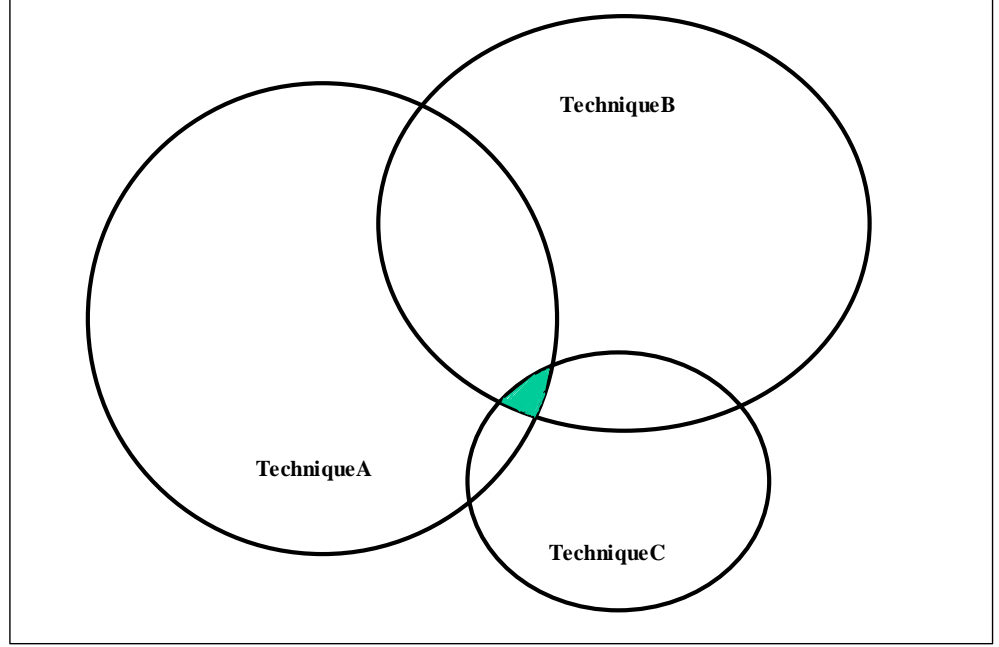

Figure 3

The Effect of Multiple Analyses on Attribution

\subsection{Sensitivity}

Sensitivity of the analytical techniques will be particularly important when the amount of evidence is small. In some cases, smugglers may initially deliver only a tiny sample, which is purportedly representative of a much larger batch of material, to their customer. Even for interdictions of large amounts of material, the analytical techniques should be as sensitive as 
possible, because trace species are often significant components of a signature. However, as the sensitivity of the analysis increases, so does the susceptibility to contamination and other interferences. For example, the analyst might have to decide whether the Fe and $\mathrm{Cr}$ detected in the analysis is the signature of a certain manufacturing process or merely contamination from a stainless steel spatula used to collect the evidence.

\subsection{Communication of Results}

All results and assessments must be communicated in the form of a technical report. For investigations in which the INFL provides assistance to the Member State, communication of the final report constitutes completion of the nuclear forensics assistance (see Option 6 in Appendix A). Any particular requirements that the Member State may have regarding the final report, such as accompanying meeting or verbal briefing, should be included in the SOW.

Reports may be issued periodically during and after the conclusion of an interdiction event to keep decision makers apprised of recent data and insights from the investigation. For example, the laboratory could issue reports to coincide with the availability of results from the sequence of techniques and methods in Table 2 ( 24 hours, 1 week, 2 months). However, a final report must also be issued after the conclusion of the event. The nuclear forensics laboratory should identify all data and other information used in the assessment and include the rationale for the conclusion. The laboratory should also identify any information that conflicts with the assessment and why they are choosing to disregard or discount that information.

Ideally, there should be an unambiguous method of identifying the confidence level of all conclusions to decision-makers. For example, one could imagine communicating the confidence level of attribution assessment using broad categories, such as "Highly Certain," "Probable," "Possible," and "Unattributed." The international nuclear attribution community has not yet reached a consensus on such a method. It is difficult to summarize a vast body of evidence, each with its own uncertainty, with a single categorization. However, such a categorization must be made to communicate the strength of the evidence to decision makers who might not have the requisite technical background to rigorously evaluate all stages of data acquisition and analysis. 


\section{Next Steps}

The field of nuclear forensics and attribution is an emerging discipline. Most of the initial work has been performed independently, with some collaboration, by national and international laboratories in the developed world. There is a general agreement on the iterative approach to nuclear attributions. This approach must take advantage of a knowledge base of processes to predict physical, chemical, elemental, or isotopic signatures that can be measured and the "tool box" of analytical techniques that can verify the presence or absence of these signatures.

\subsection{The INFL Menu of Options}

The full Menu of Options for accessing the expertise of the INFL is presented in Appendix A. The various options have already been discussed as they apply to specific points in the Model Action Plan. The options range from initial contact, to on-site and holding site assistance, to transportation assistance, to actual nuclear forensic analysis or attribution. The Member State can initiate one of these options by contacting the IAEA to establish contact with the INFL.

The SOW (see Option 5 in Appendix A) provides the basis for the state-to-state bilateral agreement that enables the assistance of an INFL laboratory. However, because nuclear forensics and nuclear attribution are dynamic and iterative processes, a Forensics Management Team, which includes a representative from the Member State and from each participating INFL laboratory, will operate throughout the entire investigation to make decisions about the course of analysis.

As described in Section 6.2, the likelihood of a successful attribution is increased by allowing the broadest set of experts possible to participate in the process. Therefore, it is highly recommended that the Member State authorize the participation of multiple INFL laboratories or, at least, the sharing of information between multiple INFL laboratories in the SOW. However, the Member State always controls access to the evidence and the sharing of information through the SOW.

Recipients of this document should consider providing copies to those people designated as first responders to an incident. In particular, these first responders should highlight Options 1 and 2 of the Menu of Options (Appendix A) for their future use should the need arise.

\subsection{Tabletop Exercises}

Because the discovery and interdiction of nuclear material often involve overlapping jurisdictions (local and national law enforcement, nuclear and hazardous material regulatory bodies, etc.), it is important for countries to address any potential legal or political obstacles prior to the occurrence of an actual incident. For example, national regulations for transporting nuclear material may prevent the shipment of interdicted material outside the country to a nuclear forensics laboratory. Safety regulations may preclude the seizure of nuclear material 
without steps that destroy potential forensic evidence. Executing a "tabletop" exercise allows all of the operational participants to work through a hypothetical incident on paper to discover potential problems without the serious consequences associated with an actual incident. A tabletop exercise also allows the formulation of rigorous policies and procedures with the benefit of more time and deliberation than an actual incident might allow.

\subsection{Investment in Research \& Development}

Finally, although there is general agreement on the approach to nuclear attribution, continuing research and development $(\mathrm{R} \& \mathrm{D})$ is essential, because the field is so new. International collaboration in the field of nuclear forensics, leading to cross-country R\&D efforts, will provide maximum leverage for each country's R\&D investments. The existing threat posed by diverted nuclear materials in the hands of criminals or terrorists makes these high payback investments.

One area that requires continuing effort is the development of knowledge databases for nuclear sites and processes. Because each nuclear country often uses its own materials and processes, which are either classified or proprietary, this effort requires international collaboration.

Attention should be focused on developing the databases and search tools necessary to access comprehensive national and international databases and worldwide nuclear expertise. Such databases must be designed to provide the maximum amount of information to participating countries without compromising restricted information.

Additional effort is also needed in identifying and exploiting new radioactive and traditional forensic signatures. For example, there has been promising research into using natural variations in stable isotopes or the presence of trace organic or biological material as unique forensic signatures. More extensive work is required to make such methods routinely useful for nuclear attribution.

Furthermore, improvements in analytical instrumentation and method, particularly in the areas of increased precision, improved sensitivity, and decreased spatial scale will lead to concomitant improvements in the data used for nuclear attribution.

\subsection{Nuclear Attribution as a Preventative Measure}

Nuclear attribution allows authorities to discover and understand illicit trafficking in nuclear material before any sinister plans progress to the point of actually developing, deploying, and exploding a nuclear weapon or RDD. The earliest clue that we might have to such plans is the discovery of efforts to obtain the nuclear or radiological material itself. It is important to pursue cases that at first glance do not appear to be that important, e.g. small amounts of material or lesser-enriched HEU, because they may be linked to more serious threats that will emerge later, that is, they are early precursors. The early discovery of such efforts may be one of our best opportunities - allowing sufficient time to stop deadly plans before they progress to completion with all of the attendant damages to life, property, and international security. 


\section{Appendix A. Menu of Options for ITWG Assistance}

Purpose: The following checklist provides a series of steps to be taken by a member state to evaluate and then request assistance from the ITWG Nuclear Forensics Laboratories (INFL).

\section{Initiate Contact with Nuclear Forensics Experts}

- Contact the IAEA for assistance in evaluating the need for nuclear forensics and to obtain INFL contact information

- Communicate to the INFL contact person the potential need for nuclear forensics assistance

- Set-up telecommunications channels with INFL and IAEA contacts

\section{On-Site \& “Holding Site” Advisory Assistance}

Informal assistance can be quickly provided on-site (or later at a "holding site") via telecommunications with a team of nuclear forensics experts:

- Request advice on categorization of radioactive materials (i.e. special nuclear material, reactor materials, and commercial/radioactive sources)

- Advice on radiation detectors for performing categorization analysis

- Assistance in interpreting spectra from on-site radiation detectors

- Availability of experts to perform categorization analysis

- Request advice on collection of evidence (nuclear and non-nuclear)

- Request advice on preservation of evidence

\section{Transportation Assistance}

This section covers requests for assistance in transporting materials from a holding site to a laboratory capable of nuclear forensics analysis, i.e. an INFL Laboratory; transportation within country from the incident scene to an appropriate holding facility is assumed to be needed so quickly that external assistance is not feasible.

- Request guidance on packaging and transportation to meet legal requirements (IAEA assistance)

- Obtain guidance on preventing cross-contamination in packaging and transportation (IAEA and INFL)

- Request IAEA assistance for packaging and transportation to identified INFL Laboratory (see next step) 


\section{Identification of INFL Laboratory(ies) to provide assistance}

This step involves identifying the desired level of nuclear forensics analysis and the lab(s) that will provide it

- Obtain from the INFL contact the current list of INFL Labs that can provide a nuclear forensics analysis of the sample

- Determine the desired level of destructive analysis

1. Basic characterization determines the nature of the material, i.e. physical structure and major element composition (by optical and scanning electron microscopy) and isotopic composition (by gamma-spectroscopy and mass spectroscopy)

2. Technical attribution of material origins

- Potential types of additional analyses are given in the attached TechDoc

- May include non-nuclear forensics on associated materials

- May include classical forensics on radiologically-contaminated materials

- Identify potential INFL Lab(s) for nuclear forensics assistance (with INFL and IAEA contacts)

- Contact potential INFL Lab(s) to start process of establishing a bilateral agreement

- Potential Laboratory/State may decline to offer assistance

- Actual investigation will be carried out on a State-to-State basis

\section{Development of Statement of Work}

A Statement of Work provides the basis for The State-to-State bilateral agreement

口 Establish the "Forensics Management Team"

- FMT expected to operate throughout investigation, from transportation to final report

- Detail the organization and functioning of FMT, e.g. one POC for your country and each participating laboratory

- Consider including more than one nuclear forensics laboratory for best interpretation (either by multiple bilateral agreements or by allowing primary Lab to work with other identified Labs)

- Establish special requirements, e.g. rules of evidence, chain-of-custody, sharing of information, non-disclosure agreements

- Establish expectations for communication, e.g. frequency of communication, types of decision points that require prior approval, initial reporting of results

- Identify "phases" for investigation, e.g. start with basic characterization, possibly followed with technical attribution of origins

- Agree on disposition of materials remaining after the investigation is completed

- Specify the expected timeline for the nuclear forensics analysis \& final report

- Specify types of information to be included in the final report

- Obtain necessary government approval for each party to the agreement 


\section{Completing the Work}

Communication of the final report by the Nuclear Forensics Lab(s) to the requesting state constitutes the completion of the nuclear forensics assistance

- The final report may be accompanied by a verbal briefing

- The requesting state is encouraged to provide feedback to the IAEA

- Evaluation survey provided by member state to IAEA

- At the discretion of requesting state, release final report to the IAEA 


\section{Appendix B. Tools for Radioactive Analysis}

\section{Bulk Analysis Tools}

\section{Radiochemistry}

One of the most sensitive methods for detecting radioactive elements is radiochemistry. The elemental constituents of different radionuclides are separated from each other based upon chemical differences. The radioactive isotopes in the separated samples are then quantified using radioactive counting methods (alpha, beta, or gamma-counting methods) as referenced to an internal isotopic standard, called a "spike." The chemical separation step increases both the sensitivity and the selectivity of the technique.

\section{Isotope Ratio Mass Spectrometry}

Isotope ratio mass spectrometry is used to determine the isotopic composition of elements in the material. Isotope ratio mass spectrometry can also provide quantification (often called an "assay" when applied to major constituents of the sample) of these elements using a spike. Mass spectrometric methods are able to determine both radioactive and stable isotopes. In mass spectrometry, sample material is converted into positively or negatively charged ions. The resulting ions are then separated according to their mass-to-charge ratio and the intensities of the resulting mass-separated ion beams are measured. Elemental mass spectrometric techniques generally have high selectivity due to the mass analysis step, except in specific cases of isobaric interferences. In general mass spectrometry offers extremely high precision and accuracy of analysis as well as high abundance sensitivity.

In thermal ionization mass spectrometry (TIMS), a chemically separated and purified sample is deposited on a metal filament, which is then heated in a high vacuum by passing a current through it. If the ionization potential of a given element is low enough, compared to the work function of the filament, then a fraction of the atoms of that element are ionized via interaction with the filament surface at high temperature. The specificity of the TIMS analysis can be provided both by the chemical separation step and the ionization temperature. TIMS is capable of measuring isotopic ratios on picogram $\left(10^{-12} \mathrm{gram}\right)$ to nanogram $\left(10^{-9} \mathrm{gram}\right)$ of sample (tens of femtograms $\left(10^{-15}\right.$ grams) using special pre-concentration techniques). As well, TIMS routinely measures differences in isotope mass ratios on the order of 1 in $10^{6}$.

In inductively coupled plasma mass spectrometry (ICP-MS,) the sample is aspirated as a solution into an inductively coupled plasma, where the high temperature of the plasma breaks the sample down into its constituent atoms and ionizes these species. In addition to measuring isotope ratios, ICP-MS is useful both as a sensitive elemental survey tool and as a method for precisely quantifying trace elemental constituents of a sample. The detection limits range from $0.1 \mathrm{ppb}$ (parts per billion) to a few tens of ppb in solution. ICP-MS has difficulty measuring some elements due to background, interferences, or poor ionization efficiency (e. g., C, O, P, K, S, and $\mathrm{Si})$. 


\section{Glow Discharge Mass Spectrometry}

In Glow Discharge Mass Spectrometry (GDMS), the sample serves as the cathode of a glow discharge (usually argon is the support gas). The sample is sputtered by argon ions and the sputtered neutrals from the sample diffuse into the plasma. In the plasma, the neutrals are ionized either by electron impact or, more typically, by collision with metastable argon atoms (Penning ionization). GDMS can be an effective technique for measuring bulk samples, such as dirt, directly. GDMS is highly quantitative, suffering from very few matrix effects. GDMS can be used a sensitive survey tool with detection limits ranging from less than $1 \mathrm{ppb}$ to a few ppm, depending on the element. However, GDMS lacks the precision associated with radiochemistry, TIMS, or ICP-MS. It also can provide misleading results for some heterogeneous samples, since the sampled volume is small and there is no sample homogenization provided by dissolution or a similar process.

\section{X-Ray Analysis}

X-ray fluorescence (XRF) can also be useful for broad and non-destructive elemental quantitation of a sample. An incident X-ray beam excites characteristic secondary X-ray wavelengths and energies in a solid sample that are counted on a solid-state or proportional counter. The detection limits for XRF are in the range of $10 \mathrm{ppmw}$. Analysis of the light elements is possible but more problematic due to low characteristic x-ray energies. However, XRF is strictly an elemental analysis tool, while ICP-MS or GDMS, which are more sensitive, are able to measure isotopic composition. XRF can be performed directly on solid samples, although dissolutions are often analyzed to provide homogenization of the sample.

X-ray diffraction (XRD) is the standard method for identifying the chemical structure of inorganic and organic crystalline materials. X-ray beams that impinge on regularly ordered lattices undergo constructive and destructive interference that depends on the spacing of the lattice, the wavelength of the X-rays, and the angle of incidence of the X-ray beam. By rotating the sample relative to a fixed X-ray source, variations in interference occur, leading to diffraction patterns. These diffraction patterns can be compared to reference spectra to identify the specific crystalline phase. Note that XRD cannot generate diffraction patterns from amorphous (noncrystalline) material.

\section{Gas Chromatography/Mass Spectrometry}

Gas chromatography/mass spectrometry (GC/MS) is a technique useful for detecting and measuring trace organic constituents in a bulk sample. In GC/MS, the components of a mixture are separated in the gas chromatograph (GC) and identified in the mass spectrometer. The primary component of a GC is a narrow bore tube (called a "column"), which is maintained inside an oven. In the simplest arrangement, the mixture is flash vaporized in the heated introduction port. The various components of the mixture are swept onto, and through, the column by the carrier gas (usually $\mathrm{He}$ ). The components of the mixture are separated on the column based upon their relative affinity for being on the column material versus the carrier gas. Columns are usually coated with a special material to enhance separation of the components of interest. In the ideal case, all components are separated and introduced into the mass 
spectrometer one at a time. At low flow rates, the column effluent can be introduced directly into the mass spectrometer. At higher flow rates, the $\mathrm{GC}$ requires an interface to match the flow requirements of the mass spectrometer, usually by selectively removing the carrier gas.

The mass spectrometer ionizes each component as it elutes from the column. Many different ionization methods can be used, but the most common for GC/MS is electron impact (EI). In EI, an energetic $(70 \mathrm{eV})$ beam of electrons bombards the sample molecules. Some of these electrons will hit a sample molecule and knock out an electron, leaving the molecule positively charged. This ionizing collision tends to impart some energy to the molecule. This energy is sometimes great enough to cause the ion to fragment (usually into an ion and a neutral fragment) in ways characteristic of the molecule's structure. The relative abundance of ions of various masses (strictly mass-to-charge ratio, although the typical ion charge in EI is usually 1) is characteristic of the intact molecule. The mass spectrometer measures the intensity of ions of various masses, either by simultaneous or sequential detection, depending on the type of mass spectrometer. The resulting plot of relative intensity versus mass-to-charge ratio is a "mass spectrum." There are now extensive libraries of EI mass spectra that help identify unknown compounds that are separated and detected by the GC/MS.

\section{Imaging Tools}

\section{Optical Microscopy}

Optical microscopy is often the first method to examine the sample at high magnification. An optical microscope uses magnifying light optics and reflected or transmitted methods of sample illumination to present magnified images of the sample to the user's eyes. Light microscopes can readily magnify an image up to $\mathrm{x} 1000$.

\section{Scanning Electron Microscopy}

Scanning electron microscopy (SEM) can provide image magnifications up to x10000 with a conventional thermal filament source or x 500000 times with a field emission source. In SEM, a finely focused electron beam is rastered over the sample. The interaction of the energetic incident electron beam and the sample produces backscattered electrons, secondary electrons, and X-rays. By measuring the flux of one of these types of particles as a function of raster position, an image or map of the sample can be reconstructed and displayed. Each type of particle conveys different information about the sample and, therefore, offers a different contrast mechanism. For instance, secondary electrons carry information about sample topology. Backscattered electrons carry information about average atomic number of the area being imaged and can be used to quickly detect spatially resolved phases of contrasting chemical composition.

\section{Transmission Electron Microscopy}

In transmission electron microscopy (TEM), the energetic electron beam is transmitted through a ultra-thin sample ( 100 nanometers thickness). TEM is capable of higher magnifications (several million times) than SEM and is able to image extremely fine structure, but at the expense of tight restrictions on sample thickness. In most cases, thin sections of the sample must 
be made. Transmitted electrons can undergo diffraction effects, which can be used like XRD to determine crystal phases in the material.

\section{Microanalysis Tools}

\section{X-Ray Microanalysis}

The X-rays generated during SEM or electron microprobe analysis carry elemental information and are a convenient way of measuring the elemental composition of micro-samples or particles. The X-rays can be analyzed be either of two methods. First, an energy dispersive spectrometer (EDS) uses a solid state detector (typically a SiLi detector) to measure simultaneously the energy and rate of incident X-rays. Second, a wavelength dispersive spectrometer (WDS) uses an synthetic analyzing crystal to sequentially diffract selected X-rays into a gas proportional counter. Due to the interaction mechanics of the electron beam with the sample, X-rays are generated over approximately a $\sim 1 \mu \mathrm{m}$, tear drop-shaped region. Thus, X-ray analysis is limited to spatial resolution of around $1 \mu \mathrm{m}$. The detection limits of X-ray analysis are approximately $.01-.1 \%$, depending on the element. Therefore, $\mathrm{X}$-ray analysis is not a technique for analyzing trace elements in forensic samples.

\section{Secondary Ion Mass Spectrometry}

Secondary ion mass spectrometry (SIMS) can be used for both elemental surveys and isotopic analysis of small samples, even particles. SIMS uses a finely focused primary ion beam, e.g., $\mathrm{O}_{2}{ }^{+}, \mathrm{Cs}^{+}$, or $\mathrm{Ga}^{+}$, to sputter the sample surface. The sputtering process produces secondary ions (ions characteristic of the sample) that can be analyzed by a mass spectrometer. The SIMS process is very matrix-dependent, so accurate isotopic quantitation requires closely matched standards that sputter identically to unknowns. SIMS is also capable of acquiring microscopic images of isotopic distributions (which can correspond to elemental images for known elements of known isotopic abundance). In the "microscope" mode, a relatively large primary ion beam bombards the sample and the spatial position of the resulting secondary ions is maintained and magnified throughout the mass spectrometer. An imaging detector then displays and records the resulting isotopic image. In the "microbeam" mode, a finely focused primary ion beam is rastered across the sample, in a manner similar to an electron microscope. The resulting secondary ion signal is then measured and correlated with the position of the primary ion beam to generate the isotope image. Sample ablation of the focused ion beam on the sample yields a depth profile through the sample surface that is extremely valuable to document compositional gradients or surface alteration.

\section{InfraRed Spectroscopy}

InfraRed Spectroscopy (IR) is useful for the identification of organic compounds. Through the use of a specialized microscope, IR can be performed on samples as small as $15 \mu \mathrm{m}$ and is an important microanalytical technique. Molecular bonds vibrate at characteristic frequencies. If a particular molecular vibration results in a change in the bond's dipole moment, then the molecule can absorb infrared radiation of that characteristic frequency, exciting that vibration. 
In IR, one irradiates the sample with a broad band of infrared frequencies and then measures the intensity of the reflected or transmitted infrared radiation as a function of frequency. From the knowledge of incident intensity and reflected/transmitted intensity as a function of infrared frequency, one can reconstruct an infrared absorbance spectrum. Absorption at specific frequencies is characteristic of certain bonds. Thus, the IR spectrum identifies the various bonds and functional groups within the molecule. In addition, there are also vast libraries of IR spectra that help identify unknown compounds or, at least, place them into certain classes of molecules.

Most IR spectroscopy today is performed by Fourier Transform IR (FTIR) instruments. These instruments measure the intensity of infrared radiation as a function of frequency by use of an automated interferometer. The interferometer produces a signal whose intensity varies with time. The Fourier transform of that signal yields a spectrum of intensity versus wavelength. FTIR is more sensitive than other methods of IR, meaning that it produces a better quality spectrum in a shorter amount of time. 
Survey

Table B-1

Summary of Analytical Tools

\begin{tabular}{|l|c|l|}
\hline Technique & $\begin{array}{c}\text { Type of } \\
\text { Information }\end{array}$ & $\begin{array}{l}\text { Typical } \\
\text { Detection } \\
\text { Limit }\end{array}$ \\
\hline $\begin{array}{l}\text { High Resolution } \\
\gamma \text {-ray }\end{array}$ & Isotopic & \multicolumn{1}{|c|}{ ng-ug } \\
\hline
\end{tabular}

Bulk

\begin{tabular}{|l|c|c|}
\hline Technique & $\begin{array}{c}\text { Type of } \\
\text { Information }\end{array}$ & $\begin{array}{l}\text { Typical } \\
\text { Detection } \\
\text { Limit }\end{array}$ \\
\hline Radiochemistry & Isotopic & $\mathrm{fg}-\mathrm{pg}$ \\
\hline TIMS & Isotopic & $\mathrm{pg}-\mathrm{ng}$ \\
\hline ICP-MS & $\begin{array}{c}\text { Isotopic } \\
\text { Elemental }\end{array}$ & $\mathrm{pg}-\mathrm{ng}$ \\
\hline GDMS & $\begin{array}{c}\text { Isotopic } \\
\text { Elemental }\end{array}$ & $0.1 \mathrm{ppbw}-10 \mathrm{ppmw}$ \\
\hline XRF & Elemental & $10 \mathrm{ppmw}$ \\
\hline XRD & Molecular & $\sim 5 \mathrm{at} \%$ \\
\hline
\end{tabular}

Imaging

\begin{tabular}{|l|c|c|}
\hline Technique & $\begin{array}{c}\text { Type of } \\
\text { Information }\end{array}$ & $\begin{array}{c}\text { Spatial } \\
\text { Resolution }\end{array}$ \\
\hline Optical Microscopy & Imaging & $1 \mu \mathrm{m}$ \\
\hline SEM & Imaging & $15 \AA$ \\
\hline TEM & Imaging & $1 \dot{A}$ \\
\hline
\end{tabular}

Microanalysis

\begin{tabular}{|l|c|c|c|}
\hline Technique & $\begin{array}{c}\text { Type of } \\
\text { Information }\end{array}$ & $\begin{array}{c}\text { Typical } \\
\text { Detection } \\
\text { Limit }\end{array}$ & $\begin{array}{c}\text { Spatial } \\
\text { Resolution }\end{array}$ \\
\hline ICP-MS & $\begin{array}{c}\text { Elemental } \\
\text { Isotopic }\end{array}$ & $\mathrm{pg}-\mathrm{ng}$ & $\mathrm{N} / \mathrm{A}$ \\
\hline TIMS & Isotopic & $\mathrm{pg}-\mathrm{ng}$ & $\mathrm{N} / \mathrm{A}$ \\
\hline SIMS & $\begin{array}{c}\text { Elemental } \\
\text { Isotopic }\end{array}$ & $0.1 \mathrm{ppbw}-10 \mathrm{ppmw}$ & $.2-1 \mathrm{um}$ \\
\hline SEM/EDS or /WDS & Elemental & $0.1-2$ at\% & $1 \mathrm{um}$ \\
\hline XRD & Molecular & $\sim 5$ at\% & $\mathrm{N} / \mathrm{A}$ \\
\hline
\end{tabular}

Legend:

$\mathrm{ug}=$ nanogram $=10^{-6}$ gram

ng = nanogram $=10^{-9}$ gram

pg = nanogram $=10^{-12}$ gram

fg $=$ nanogram $=10^{-15}$ gram at $\%=$ atom percent ppmw $=$ parts per million by weight ppbw = parts per billion by weight um $=$ micrometer $\AA$ A $=$ Angstrom $=1^{-10}$ meter 


\section{Appendix C. Examples of Traditional Forensic Evidence}

\section{Documentary Evidence}

If a computer is recovered from the incident scene, then the forensic analyst must try to recover all of the information stored on the computer. Programs and files may document the perpetrators' plans and methods and/or implicate other people.

Documents or recordings (from an answering machine, for example) can provide information, not only through the message itself, but also through other evidence that ties the document or recording to a person or place. A thorough examination of a document would include detailed analysis of the handwriting on written documents, the type characteristics and anomalies on typed documents, photocopier characteristics and anomalies on photocopied documents, and mechanical impressions for typeset documents. Examination of a recording would include an analysis of the language, dialect, and stray background sounds.

Analysis of the paper used in a document can itself provide valuable clues. Paper analysis should include careful examination of the origin of and inclusions in the paper stock, any altered or obliterated writing, the use of carbon paper or correcting ink, evidence of the writing instrument used, and the true age of the document. Even the analysis of burned or charred paper can provide valuable information.

\section{Impressions}

Latent fingerprints tie a person to a location or an object seized in the incident. Shoe prints discovered at the incident site can also link a specific person to the incident site, through the unique tread pattern of their shoes. Tire treads serve to link a car to the incident site in the similar manner.

\section{Chemical Analysis}

Unique or special chemical substances seized at the incident site can provide valuable evidence. Controlled substances or poisons may provide useful information about the perpetrators or their motives. Accelerants used for arson or explosive residues provide evidence about methods and purpose. Characteristic dyes and petroleum products can tie the seized evidence to particular locations, perhaps serving as a marker for route attribution.

\section{Tissue and Hair Evidence}

Human tissue recovered at the incident scene can also tie a specific individual to the incident scene or seized evidence. Blood can be typed through serology. Blood and other tissue can be subjected to either nuclear or mitochondrial DNA analysis, again helping to implicate an individual. Hair samples provide information about race and body characteristics. The 
morphology of the hair sample may indicate how the hair was lost. Even animal hair or tissue might provide useful evidence, linking a particular type of animal with the perpetrators.

\section{Weapons Evidence}

In the event that a bomb is detonated or seized, the bomb remains and explosive residues can provide a pattern for determining the type of bomb and its method of manufacture. Unique materials in the remains may pinpoint the exact perpetrator or, at least, restrict the number of potential perpetrators through purchase records for such material.

In the event that firearms are seized, the examination of the projectile lead, cartridge cases, gunshot residues, and any altered function may tie the perpetrator to a given location, a fact useful in route attribution, or it may provide evidence of method or purpose.

\section{Tool Marks}

Alterations in objects that appear to be made by the perpetrators themselves are highly significant. The forensic analyst should look for fractures (particularly those that match up with other fractures in the evidence), odd marks in wood, the use of stamps and dies, and the modification of locks and keys. The forensic analyst should attempt to restore any obliterated markings.

\section{Fiber Examination}

Fibers can serve to tie objects and perpetrators to specific locations as well. The forensic analyst must pay particular attention to fiber evidence, such as fabrics, cords, and ropes and determine its type: animal (wool), mineral (glass), synthetic, or organic (cotton). The forensic analyst should also examine all evidence for feathers, plant material, pollen, or spores that are indicative of a location other than the incident site. These botanical pieces of evidence can be important for route attribution.

\section{Other Materials Evidence}

Other associated evidence should be carefully examined for possible clues towards methods and route attributions. Such materials as cosmetics, paints, plastics, polymers, metal objects, and tapes often vary in chemical composition from place to place. Unique characteristics in these materials might tie the perpetrators to a specific location, again a fact that can be important for route attribution. In the same way, unique minerals found on the evidence might be diagnostic of specific geology and location (i.e., geolocation). 


\section{Appendix D. Nuclear Forensics and Smuggling Scenario}

\section{Introduction}

The following is a hypothetical scenario involving the interdiction of nuclear material illegally transported across national borders. The purpose is to describe how such material might be discovered and the subsequent steps to determine the source of this material and prosecute those responsible. The objective is to provide decision-makers and responders with a worked example of a conceivable episode involving smuggled nuclear materials and the ensuing attribution process. The scenario follows the model action plan conceived by the Nuclear Smuggling International Technical Working Group (ITWG). This case incorporates elements of actual case files and data, but is a fictional example.

\section{A Scenario}

An Uzbekistan Airlines arrives in Borispol Airport in Kiev, Ukraine, after a four-hour direct flight from Tashkent. The passengers disembark the aircraft and enter the passport control and customs area. During this process, an Uzbekistan national approaches the Ukrainian passport officer and presents his passport. The male passenger is in his late 20's and states his business as that of a foods distributor who is attending business meetings in Kiev. He explains that he is distributing preserved fruits from the Fergana Valley to new and emerging markets in the Ukraine and other major cities in eastern Europe. Despite his modest dress and young age, his entry forms state he will be staying in one the most exclusive hotels in Kiev during his planned two day stay in the Ukraine. The customs officer detains the new arrival for further questioning.

During a search of the individual's single piece of luggage, customs officials discover two small, clear glass vials approximately $2 \mathrm{~cm}$ in diameter and $10 \mathrm{~cm}$ long with screw caps. The vials contain a fine-grained, poorly sorted powder of high density. The vials are unmarked and the caps are further secured with plastic electrical tape. Together with the vials is a Kiev city map with various names and telephone numbers written along the margins. The customs officials are suspicious of the powder and use a thin-window Geiger-Mueller beta-gamma pancake detector at the airport to determine that the material is radioactive.

Within an hour, the suspect is apprehended by the local police force, the two vials are removed from his luggage and placed in plastic bags, and his luggage is confiscated. The suspect and the luggage are transferred to a local police station. While the suspect is further interrogated, the police call the State Nuclear Regulatory Committee of the Ukraine (SNRCU) for direction on how to proceed with the collection of radioactive evidence. The SNRCU response is in accordance with an illicit nuclear trafficking handbook developed in 2000 after the model action plan of the ITWG. 


\section{Collection and Transport of Radioactive Evidence}

Within several hours, the vials in the plastic bags are photographed with a digital camera at the airport and notes are taken of the approximate size, constituent radioactivity, condition, and labeling associated with the confiscated powder samples. The vials are carefully placed in a shielded transport container provided by Ukrainian nuclear authorities. The container is sealed with a tamper-proof mechanism. Information on the initial field survey data is included with the samples in the transit container. The samples are transported by escort to a local nuclear institute equipped to handle and analyze radioactive materials. Once at the institute, the container is transferred into a ventilated hood in the secured receival laboratory. Using alpha and betagamma handheld radiation monitors, the shipping container is carefully opened, the threat of removable contamination is evaluated, and the plastic bags with the vials are removed. Once in the hood, investigators photograph the unopened vials in the plastic bags with a digital camera, being careful to avoid contaminating the vials.

Back at the police station, the suitcase is also photographed using the digital camera; the contents are inventoried, and each item is searched thoroughly. In addition the bag is thoroughly searched for hidden contraband. As part of the evidence collection protocols, representatives from the nuclear institute take swipe samples from the inside of the bag to assay for other removable evidence.

\section{Radioactive Evidence Collection and Distribution}

Radiochemical analyses are initially focused on determination of the isotopes present in the sample and a quantitative measure of the radioactivity. In addition, there is the need to determine whether the two metal powder samples are chemically and isotopically similar. Within 24 hours of their being seized, the samples are photographed in the bottle and the sample and bottle weighed. To preserve the sample, the powders are analyzed using nondestructive radiometric analysis including fixed detector gamma spectroscopy and alpha spectrometry. These results confirm that both powders are uranium oxide substantially enriched in ${ }^{235} \mathrm{U}$ (Table $1)$.

Table D-1

Isotopic Abundance of Two Seized Sample Powders

\begin{tabular}{|l|l|}
\hline Isotope & Abundance (\%) \\
\hline${ }^{232} \mathrm{U}$ & $(0.56 \pm 0.1) \times 10^{-7}$ \\
\hline${ }^{234} \mathrm{U}$ & $0.96 \pm 0.8$ \\
\hline${ }^{235} \mathrm{U}$ & $90.01 \pm 0.3$ \\
\hline${ }^{236} \mathrm{U}$ & $0.67 \pm 0.1$ \\
\hline${ }^{238} \mathrm{U}$ & $8.365 \pm 0.1$ \\
\hline
\end{tabular}

In addition milligram aliquots of the sample are fixed on an electron microscopy stub and are imaged using secondary electron microscopy with an energy dispersive analyzer at 
magnifications up to $\mathrm{x} 5000$ to determine particle composition, morphology, sorting, and size range. The SEM imagery illustrates the samples are dispersed uranium particles. Minute rods, angular fragments, plates, and small aggregates are all present (Figure 1).

\section{Figure D-1 \\ SEM Image of Dispersed Uranium Oxide Particles Exhibiting Irregular Morphologies}

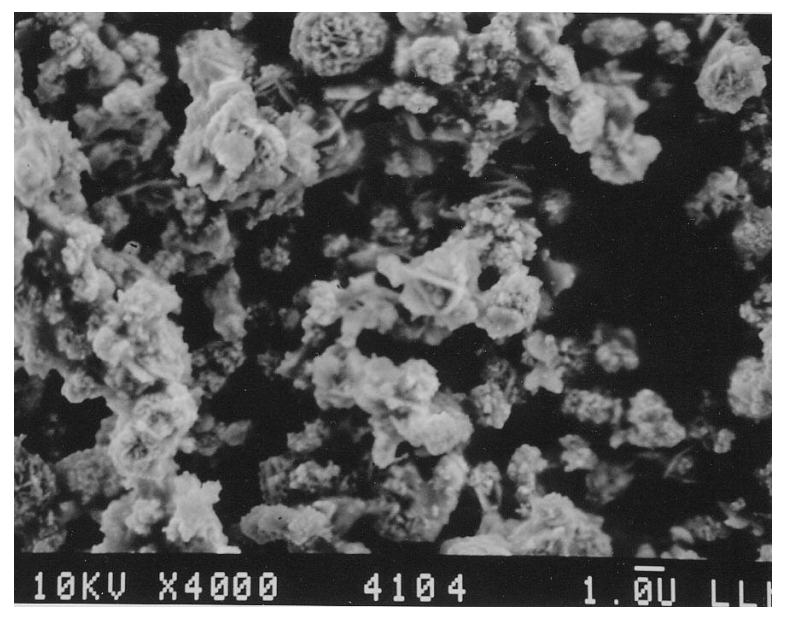

The nuclear institute is hampered in its forensics analysis by the lack of sophisticated instrumentation that allow for high sensitivity isotopic measurements, trace element analysis, or detailed study of particles and a lack of on-site technical staff with experience in nuclear forensics. Because the Ukrainian authorities have patterned their nuclear smuggling response planning around the model action plan of the ITWG, this alliance allows the considerable experience of the international smuggling community to be brought to bear on this case.

At the request of the Ukrainians, a state-of-the- art nuclear forensics laboratory in central Europe undertakes further analysis. Aliquots of the samples are packed in secured and shielded containers, chain of custody is established, and the entire package is sent by courier to the European laboratory for comprehensive forensic analysis. One week after the intercept, the samples are logged in at the European laboratory and distributed for analysis. The choice of analyses was agreed upon after consultation with the Ukrainian authorities and with input from experts with experience working on cases of this kind. Instrumental methods employed in the analysis include thermal ionization mass spectrometry to determine major and minor isotope abundance with high sensitivity and precision, inductively coupled plasma mass spectrometry to determine trace elemental abundances, and x-ray diffraction to determine the principal matrix phases. Individual micron sized particles are also analyzed for their isotopic heterogeneity using secondary ion mass spectrometry (SIMS). All analyses conform to written technical implementing procedures; standards and spikes are documented and so identified in the implementing procedures.

$\mathrm{X}$-ray diffraction results of central laboratory analyses indicated that the powders consist of $42 \%$ $\mathrm{U}_{3} \mathrm{O}_{8}$ (uranium oxide) and $58 \% \mathrm{UO}_{3} \bullet 2 \mathrm{H}_{2} \mathrm{O}$ (schoepite). Trace elemental analysis identified 74 elements. Concentrations of major impurities in the powders include $\mathrm{Cl}$ at 26 parts-per-million 
by weight (ppmw) and $\mathrm{Fe}$ at $10 \mathrm{ppmw} . \mathrm{Cr}, \mathrm{Mn}, \mathrm{Ni}, \mathrm{Cu}$, and $\mathrm{Zn}$ are present at parts-per-billion by weight (ppbw) concentrations. Mass spectrometry and particle analysis by SIMS confirm the initial radiochemical isotopic survey and indicates an enrichment of $\sim 90$ atom $\%{ }^{235} \mathrm{U}$. Plutonium is present in ppb concentrations with isotopic abundances of ${ }^{239} \mathrm{Pu}$ and ${ }^{240} \mathrm{Pu}$ at $\sim 65$ atom\% and 25 atom\% respectively.

\section{Collection of Traditional Evidence}

The single piece of luggage and it contents, including the Kiev city map and the vials containing the uranium powders are analyzed for traditional forensic clues. The glass vial and the electrical tape used for sealing are analyzed for fingerprints, and the luggage swipes are analyzed for other particles. In addition, the names and addresses written on the city map are run through pertinent law enforcement databases to check for full identification and outstanding warrants. The results from the fingerprint analysis confirm the identity of the individual presented on the passport to customs officials at the Borispol Airport. His criminal record includes only arrests for petty crimes. Particles recovered from the luggage include some sand and coarse-grained particulates. These particles are sent to the electron microscope at the nuclear institute for analysis. The particles contain $\mathrm{Be}, \mathrm{U}, \mathrm{SO}_{4}, \mathrm{Cu}, \mathrm{Zn}, \mathrm{Ca}$, and $\mathrm{Mg}$ at ppmw concentrations. The numbers and names on the map correspond to cellular telephones registered to Turkish nationals. This data is retained in a case file prepared by the Ukrainian national police.

\section{Case Development and Prosecution}

Data from the local police authorities and custom officials determine that an Uzbekistan national was illegally smuggling highly enriched uranium from Uzbekistan into the Ukraine. His prior background was unknown to authorities, but this individual raised suspicion at passport control since he was young, yet booked into a high-end hotel in downtown Kiev that seemed beyond his means. Throughout extensive questioning, the individual maintains that the powders were part of his trade samples and that he has no knowledge of the material that he was carrying. He denies any intent to commit illegal acts.

Analysis of contact information seized at the time of his arrest indicates that he was transporting highly enriched uranium that he intended to sell or transfer to Turkish buyers at a location within Kiev. He was most likely a courier with no knowledge of the larger smuggling operation. Analysis of the isotopic abundance of the interdicted samples indicates that it was weapons grade uranium. Because of its chemical and isotopic homogeneity, it most likely came from a single source. Several grams of the uranium were intercepted, and this quantity is not enough to make an improvised nuclear device; however, this material could be used in a dispersal device or for related criminal activities. No other couriers were stopped and it is unknown whether this incident represented a part of a larger smuggling enterprise.

The isotopic abundance of the major and minor isotopes of uranium, morphological characteristics of the uranium powder, the identification of constituent oxides, analysis of Be, $\mathrm{Cu}$, and $\mathrm{Zn}$ grains taken from the luggage, and examination of cellular telephone call records provide clues to the source and transport routes of the smuggled materials. Analytical results are 
compiled and compared against existing and archived isotopic and chemical data of known stocks of enriched uranium. Based on comparison with archived samples and existing data, it is probable this material originated in eastern Kazakhstan at the Ulba Metallurgical Plant. Ulba is currently a leading supplier of nuclear fuels to many states of the former Soviet Union and provided significant quantities of weapon grade nuclear fuels to the Soviet Union during the Cold War. The smuggled uranium subsequently had been transported to Tashkent where it was being passed through the Ukraine to an ultimate destination in Greece. The isotope abundance and trace elements provided diagnostic signatures that tied the interdicted powder to a source in Kazakhstan. The particles of $\mathrm{Be}, \mathrm{Cu}$, and $\mathrm{Zn}$ obtained from the luggage swipes matched manufacturing residuals from the Ulba Plant.

The suspect is apprehended and, within one month, a prosecution case is developed from the nuclear and traditional forensic evidence. Because the nuclear forensics was conducted using rigorous chain of custody procedures, standardized methods of analysis, and was comprehensively documented, the forensics evidence was admissible in subsequent legal proceedings. Ultimately, the suspect is convicted. The source of the material is definitively traced back to surplus stocks of weapons grade uranium fuel from the Ulba enrichment plant that were inadequately safeguarded in the years immediately following the breakup of the former Soviet Union.

\section{Epilogue}

Ukrainian police begin surveillance of each of the contacts listed on the city map. Over time, the police are able to establish links between each of the contacts. In addition, they note that each of the contacts make frequent trips to and from Greece. The Ukrainian police contacted Greek officials, who began surveillance of these individuals upon arrival in Greek. The Greek national police then discover that the Ukrainians were meeting with known international terrorists on a regular basis.

Over the next few months, the Central European forensic laboratory was asked to participate in two other nuclear attribution analyses - one on a sample interdicted in Amsterdam, the Netherlands, and another on a sample interdicted in Milan, Italy. In each case, the nuclear forensic laboratory found that the new nuclear material was indistinguishable from that seized in the Ukraine. At the same time that they had interdicted the nuclear material, the Dutch police had arrested a French international arms dealer and one of the international terrorists that had been spotted in Greece meeting with the Ukrainians.

Under intensive questioning by the Dutch authorities, the international terrorist confessed that his group had been attempting to acquire weapons grade nuclear material in order to fashion an improvised nuclear device. He provided sufficient information for the Greek national police to arrest 5 members of his terrorist cell, who had been using Greece as a base of operations. The Greek national police arrested 2 of the members at a secret meeting with a renegade nuclear arms expert from South Africa, whom they also arrested. 


\section{References}

[1] V. Bragin, J. Carlson, and R. Leslie, "The Categorization of Nuclear Materials in the Context of International Safeguards," ESARDA Symposium, Bruges, 8-10 May 2001.

[2] "Reduced Enrichement for Research and Test Reactors, Argonne National Laboratory website, http://www.era.anl.gov/natsec/rertr.html.

[3] "Funding for U.S.-Russia RERTR program," Analytical Center for non-proliferation problems, Review- Issue 9, http://npc.sarov.ru/english/digest/92003/appendix 8p2.html.

[4] C. D. Ferguson, T. Kazi, and J. Perera, "Commercial Radioactive Sources: Surveying the Security Risks," Occasional Paper No. 11, Center for Nonproliferation Studies, Monterey Institute of International Studies, January, 2003.

[5] G. J. Van Tuyle, T. L. Strub, H. A. O’Brien, C. F. V. Mason, and S. J. Gitomer, "Reducing RDD Concerns Related to Large Radiological Source Applications," Los Alamos National Laboratory Report LA-UR-03-6664, September, 2003.

[6] "The Nuclear Black Market," CSIS Task Force Report, Center for Strategic and International Studies, chaired by W. H. Webster, 1996.

[7] D. Albright, "Al Qaeda's Nuclear Program: Through the Window of Seized Documents," Policy Forum Online, No. 47, Nautilus Institute, November 6, 2002, http://www.nautilus.org/fora/Special-Policy-Forum/47_Albright.html.

[8] "Chronology of Nuclear Smuggling Incidents," Federation of American Scientists web-site, http://www.fas.org/irp/cia/product/go_appendixa_032796.html, 23 November 1995.

[9] "Radioactive Scrap," Steel Manufacturers Association, http://www.steelnet.org/public_policy/public_policy_environment.html.

[10] Report of the Joint Committee on European Affairs, Sub-committee on European Scrutiny, March 27, 2003, http://www.irlgov.ie/oireachtas/Committees-29th-D\%C3\%A1il/jeascedebates/JEASCES270303.rtf.

[11] "Case Study: Accidental Leakage of Cesium-137 in Goiania, Brazil, in 1987," Medical Nuclear, Biological, and Chemical On-line Information Server, http://www.nbcmed.org/ie40/Default.html.

[12] "Response to events involving the inadvertent movement or illicit trafficking of radioactive materials," IAEA-TECDOC-1313, sponsored by the IAEA, WCO, EUROPOL, and INTERPOL, September, 2002.

[13] ISO 9000:2000, "Quality management systems - Fundamental and vocabulary," International Organization for Standaridization, 2000.

[14] ISO/IEC 17025:1999, "General requirements for the competence of testing and calibration laboratories," International Organization for Standardization, 1999. 
University of California

Lawrence Livermore National Laboratory

Technical Information Department

Livermore, CA 9455

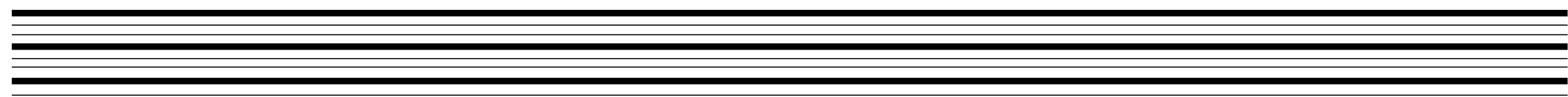

